
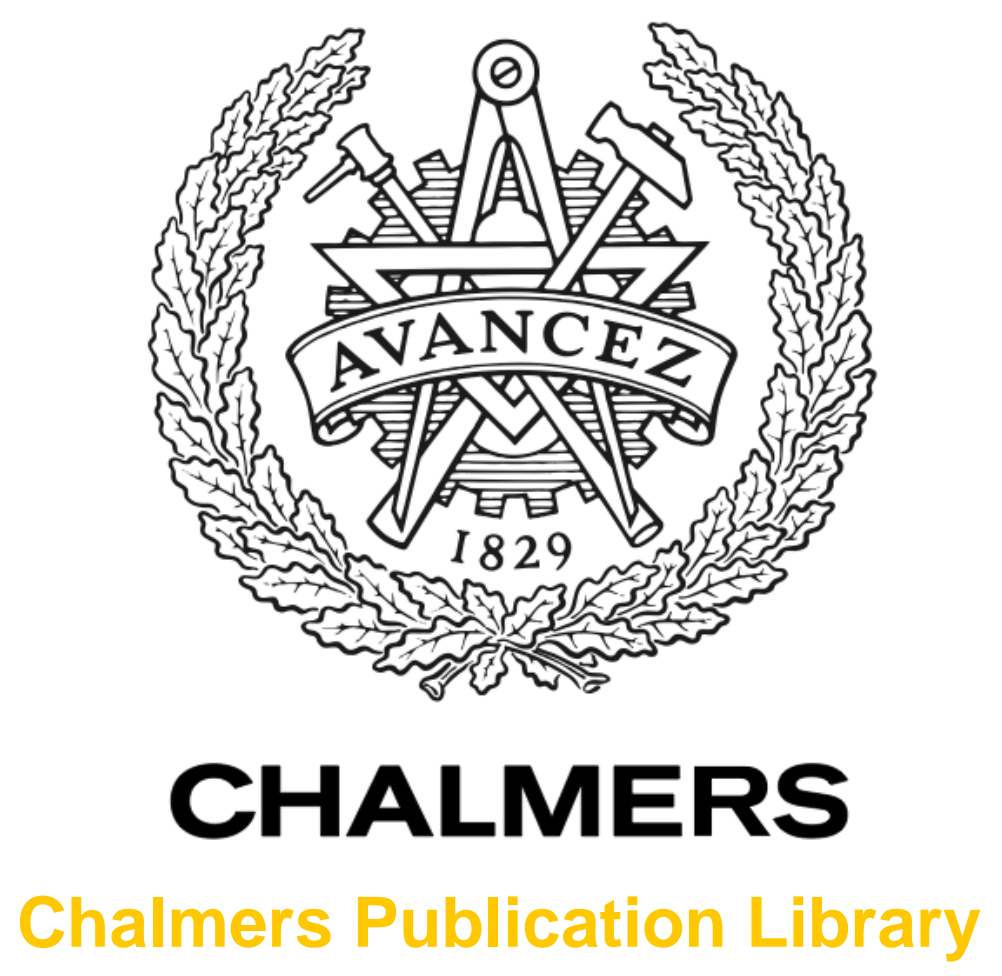

Internal force distribution in RC slabs subjected to punching shear

This document has been downloaded from Chalmers Publication Library (CPL). It is the author's version of a work that was accepted for publication in:

Engineering structures (ISSN: 0141-0296)

Citation for the published paper:

Shu, J. ; Belletti, B. ; Muttoni, A. et al. (2017) "Internal force distribution in RC slabs subjected to punching shear". Engineering structures, vol. 153 pp. 766-781.

Downloaded from: http://publications.lib.chalmers.se/publication/253568

Notice: Changes introduced as a result of publishing processes such as copy-editing and formatting may not be reflected in this document. For a definitive version of this work, please refer to the published source. Please note that access to the published version might require a subscription. 


\title{
Internal force distribution in RC slabs subjected to punching shear
}

\author{
Jiangpeng Shu ${ }^{\mathrm{a}, *}$, Beatrice Belletti ${ }^{\mathrm{b}}$, Aurelio Muttoni ${ }^{\mathrm{c}}$, Matteo Scolari ${ }^{\mathrm{b}}$, Mario Plos ${ }^{\mathrm{a}}$ \\ a Chalmers University of Technology, Gothenburg, Sweden \\ ${ }^{\mathrm{b}}$ University of Parma, Parma, Italy \\ ${ }^{\mathrm{c}}$ Ecole Polytechnique Fédérale de Lausanne, Switzerland
}

\section{A R T I C L E I N F O}

\section{Article history:}

Received 1 March 2017

Revised 17 August 2017

Accepted 2 October 2017

Available online 7 November 2017

\section{Keywords:}

Shear distribution

RC slabs

Punching shear

Nonlinear finite element analysis

Control perimeter

\begin{abstract}
A B S T R A C T
Reinforced concrete (RC) two-way slabs without shear reinforcement are commonly used in many structural systems. This paper investigated the structural behaviour of RC slabs subjected to concentrated loads leading to punching shear failure using shell and continuum nonlinear finite element analysis (NLFEA). Shear force distributions are studied for four types of slabs with different geometry of support, geometry of slab and layout of reinforcement. All factors investigated have been proven to influence the shear force distributions along the control perimeter around the support. Significant shear force redistributions due to cracking and reinforcement yielding have been observed using NLFEA. Reduced control perimeters to be used for simplified approaches accounting for calculated shear force distributions are calculated using both NLFE approaches.
\end{abstract}

(c) 2017 Elsevier Ltd. All rights reserved.

\section{Introduction}

Reinforced concrete (RC) two-way slabs without shear reinforcement are commonly used in many structural systems, such as bridge deck slabs, flat slabs of buildings and parking garages. Punching shear is a brittle failure mode usually governing the ultimate limit state for RC slabs subjected to concentrated load. In current codes of practice such as ACI 318-14 [1], EC2 [2] and MC2010 [3], the total shear strength $V_{R}$ is estimated by multiplying a nominal shear strength $v_{R}$ (shear strength per unit length) by a basic control perimeter length $b_{0}$ located at a distance of $2 d$ from the face of the column (or the edge of the loaded area) in the case of EC2 [2] and $0.5 d$ for ACI 318-14 [1] and MC2010 [3]. Research has revealed that the distribution of shear forces along the control perimeter is clearly uneven and is influenced by several factors, such as the geometry of the slab and the column, the loading and the reinforcement $[4,5]$.

In EC2 [2], these effects are accounted for by increasing the acting shear force by a factor $\beta>1.0$ as a function of the moment transfer between the column and the slab. MC2010 [3] explicitly accounts for additional effects as (i) the concentration of the shear force at the corners of large columns, (ii) the geometrical discontinuities of the slab (e.g. openings and inserts) and (iii) the presence of significant concentrated loads near the control perimeter. According to MC2010 [3], all these effects (including the effect of

\footnotetext{
* Corresponding author.

E-mail address: shuj@chalmers.se (J. Shu).
}

the moment transfer between the column and the slab) are accounted for by reducing the control perimeter to an effective control perimeter:

$b_{0}=\frac{V}{v_{\max }}$

where $b_{0}$ is the length of the shear-resisting control perimeter obtained from given shear field; $V$ is the total acting shear force and $v_{\max }$ is the maximum unitary shear force (shear force per unit length) along the perimeter. Eq. (1) is implicitly based on the assumption that redistribution of internal forces due to nonlinear behaviour may be neglected. In fact, as shown by Sagaseta et al. [6], this is a rough assumption which may be suitable for design as it is conservative.

However, how the shear force redistributes due to the nonlinear behaviour of the structure (e.g. due to bending and shear cracking and yielding of reinforcement) is also of interest. Cracking and nonlinear behaviour may modify the shear force distribution, so that the reinforcement arrangement has an influence on it (Sagaseta et al. [5]). Since it is difficult to measure the shear force distribution directly in experiments, a NLFEA can be a useful method for such an investigation. Previous studies [7] have shown that NLFEA can be an important tool to predict the behaviour of RC slabs. Among them, studies using two-dimensional (2D) models have been conducted by e.g. Menétrey [8] and Hallgren [9]. An alternative approach was investigated by researchers who implemented layered shell elements that take into account the out-of-plane shear response and allow the implementation of three-dimensional 


\begin{tabular}{|c|c|c|c|}
\hline \multicolumn{4}{|c|}{ Nomenclature } \\
\hline$B$ & width of slab & $v_{\max }$ & maximum unitary acting shear force \\
\hline$b_{0}$ & control perimeter for calculation of punching according & $V_{R}$ & shear strength \\
\hline & to EC2 & $V_{R . C A L}$ & shear strength obtained from calculation \\
\hline$b_{0, F E A}$ & the length of the effective control perimeter based on & $V_{R . E X P}$ & shear strength obtained from experiment \\
\hline$b_{0}$ & $\begin{array}{l}\text { the shear force distribution in shell and continuum FEAs } \\
\text { basic control perimeter according to MC } 2010\end{array}$ & $V_{R . F E A}$ & $\begin{array}{l}\text { shear strength slab obtained from finite element analy- } \\
\text { sis }\end{array}$ \\
\hline$c$ & size of square columns & $V_{R . E C 2}$ & shear strength obtained from calculation according to \\
\hline$c_{\max }, c_{\operatorname{mir}}$ & maximum and minimum length of a rectangular col- & & $\mathrm{EC} 2$ \\
\hline$d$ & $\begin{array}{l}\text { umn } \\
\text { effective depth of slab }\end{array}$ & $V_{R . s h e l l}$ & $\begin{array}{l}\text { shear strength obtained from calculation using CSCT } \\
\text { and shell FEA }\end{array}$ \\
\hline $\begin{array}{l}d_{c} \\
f_{c}\end{array}$ & $\begin{array}{l}\text { the diameter of circular columns } \\
\text { compressive strength of concrete }\end{array}$ & $V_{R . c o n t .}$ & $\begin{array}{l}\text { shear strength obtained from calculation using contin- } \\
\text { uum FEA }\end{array}$ \\
\hline$d_{g, \max }$ & maximum aggregate size & $\alpha$ & reduction factors for the effective control perimeter \\
\hline & maximum aggregate size $d_{g, \max }+16 \mathrm{~mm}$ & & concerning shear force concentrations \\
\hline$f_{y x}, f_{y y}$ & $\begin{array}{l}\text { yield strengths of reinforcement steel in } x \text { and } y \text { direc- } \\
\text { tion, respectively }\end{array}$ & $\beta$ & $\begin{array}{l}\text { coefficient concerning eccentric for control perimeter in } \\
\text { EC2 }\end{array}$ \\
\hline$h$ & thickness of slab & \multirow{2}{*}{\multicolumn{2}{|c|}{$\rho,\left(\rho_{x}, \rho_{y}\right)$ reinforcement ratio (in $x$ and $y$ direction, respectively) }} \\
\hline$r$ & distance of strain gauges to the centre of slab & & \\
\hline V & total acting shear force & $\psi$ & slab rotation angle in radians \\
\hline$v_{R}$ & shear strength per unit length & & \\
\hline
\end{tabular}

(3D) constitutive models, e.g. Polak [10]. Meanwhile, Belletti et al. [11-13] presented a nonlinear finite element (NLFE) approach which adopts multi-layered shell modelling of RC slabs and postprocessing of NLFE analyses (NLFEA) using the Critical Shear Crack Theory (CSCT) [15] to evaluate the punching shear resistance. In Belletti et al. $[11,12]$ NLFEA were carried out with the FE code ABAQUS and the UMAT for user subroutine in which the crack model denoted as Physical Approach for Reinforced Concrete for Cyclic Loading (PARC_CL) was implemented [14-16].

Compared to 2D element models, a 3D element model offers a higher flexibility and accuracy in the modelling of out-of-plane behaviour of RC structures and generally results in more realistic results [16-19]. According to Shu et al. [20-22], NLFEA using continuum finite elements (sometimes also referred to as solid finite elements) [16] is capable of not only predicting load carrying capacity, but also reflecting the structural behaviour of RC slabs, both in bending and shear aspects. The difference between FE analyses at different levels has been discussed in a "Multi-level Assessment Strategy for RC slabs" by Plos et al. [16]. Case studies have shown that nonlinear FE methods with continuum elements normally yield an improved understanding of the structural response.

On the other hand, shell element modelling can provide more stable results since the post-processing of NLFEA according to CSCT requires only the prediction of nonlinear flexural behaviour, avoiding all the numerical issues related to the modelling of the nonlinear shear behaviour. Furthermore NLFEA carried out using multilayered shell modelling enables us to save time and computational efforts and this aspect of use could be crucial in the case of meshes of full-scale structures or/and several load combinations. In addition, saving computing time may be useful for the probabilistic assessment which requires a large number of NLFEAs.

Therefore, the aim of this study is to investigate the behaviour such as shear force distributions in RC slabs subjected to concentrated loads by using NLFEA at different levels of modelling. According to Plos et al. [16], the modelling method at level III (shell element models) and level IV (continuum element models) are suitable. To obtain punching resistance at level III, the Critical Shear Crack Theory (CSCT) [23] can be used in combination with NLFEA. In order to study the shear force distributions in different cases, the influencing factors in terms of geometry of support, geometry of slab and layout of reinforcement are investigated. In addition, the effective control perimeter was calculated according to Eq. (1) and compared to the basic control perimeter according to MC2010 [3].

\section{Investigated slabs}

The investigated slabs were tested experimentally at École Polytechnique Fédérale de Lausanne (EPFL) from 2004 to 2015 $[5,6,24,25]$. Four slabs (PG1, PT32, PE7 and AM 04) without shear reinforcement were selected for this study; see Fig. 1 and Table 1 for dimensions and material properties. A square slab with a square column (PG1) was selected as a reference slab and the other three were selected as comparative slabs: PT32 because the reinforcement was not symmetrical; PE7 since the geometry of the slab was octagonal and the column was circular instead of square; AM04 because the column was rectangular with long side 3 times the short side. The assumption was that the variation of these factors would influence the shear force distribution. These tests were also selected because they had a high reinforcement ratios ( $\rho=0.75 \%-1.5 \%)$ so that punching occurred before reaching the plastic plateau in the load-rotation curve of the slab related to a flexural failure.

The specimens were loaded through eight concentrated forces acting on the perimeter of the specimens. The load was introduced using four hydraulic jacks placed underneath the strong laboratory floor [25]. All slabs were supported on a steel plate except PG1, which was supported by a concrete column cast together with the slab. The specimens were instrumented to measure rotations along $x$ and $y$ directions. The applied loads were measured using loading cells. Radial and tangential strains were measured at the bottom surface of slabs using omega-shaped extensometers and strain gauges, as illustrated in Fig. 1 (for PT32 as example). More details about the test set-up can be found in [5,6,24,25].

\section{Finite element (FE) analyses}

\subsection{Multi-level Assessment Strategy}

The Multi-level Assessment Strategy for RC slabs was proposed by Plos et al. [16] (see Fig. 2). The strategy provides the engineering community with a framework for using successively improved structural analysis methods for an enhanced assessment in a 


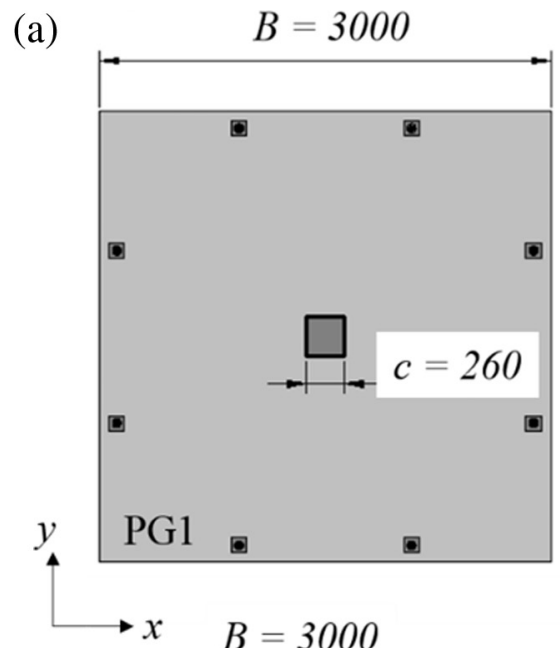

(b) Layout of reinforcement

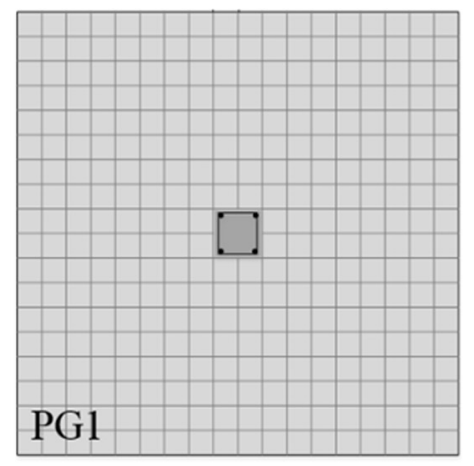

(e)

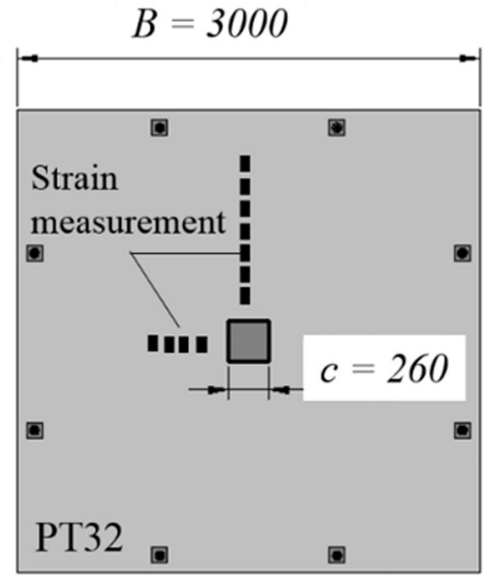

(c)

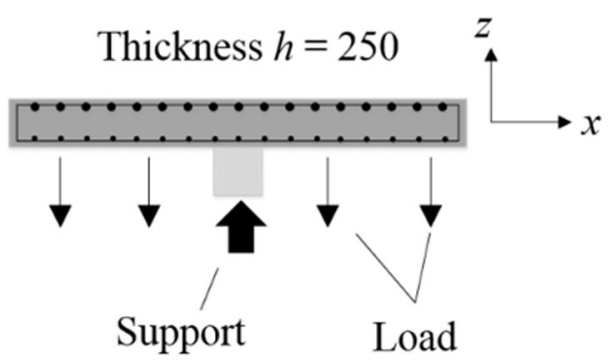

Opening for load application

(f)

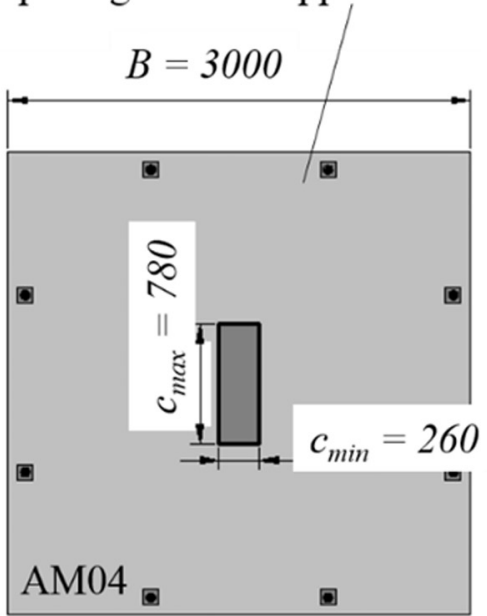

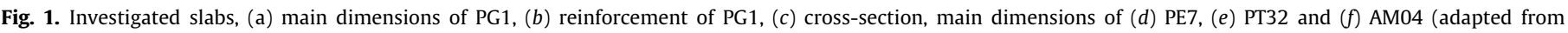
$[5,6,24,25])$; unit $[\mathrm{mm}]$.

Table 1

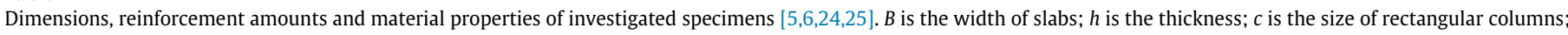

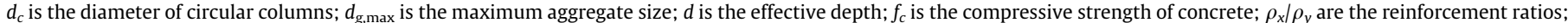
$f_{y x} / f_{y y}$ are the yield strengths of reinforcement steel (in $x$ and $y$-direction, respectively).

\begin{tabular}{|c|c|c|c|c|c|c|c|}
\hline \multirow[t]{2}{*}{ Specimen dimension [m] } & & \multicolumn{3}{|l|}{ Concrete } & \multicolumn{3}{|l|}{$\underline{\text { Reinforcing steel }}$} \\
\hline & & $\mathrm{d}_{\mathrm{g} . \max }[\mathrm{mm}]$ & $d[\mathrm{~m}]$ & $f_{c}[\mathrm{MPa}]$ & Reinforcement layout & $\rho_{\mathrm{x}} / \rho_{\mathrm{y}}[\%]$ & $\mathrm{f}_{\mathrm{yx}} / \mathrm{f}_{\mathrm{yy}}[\mathrm{MPa}]$ \\
\hline \multirow[t]{3}{*}{$\mathrm{B}=3.00 \mathrm{~h}=0.25 \mathrm{c}=0.26$} & PG1 & 16 & 0.210 & 27.6 & $\varnothing 20 / 20$ s100 & $1.50 \% / 1.50 \%$ & $542 / 542$ \\
\hline & РT32 & 16 & 0.215 & 40.0 & Ø20/16 s150 & $1.46 \% / 0.75 \%$ & $540 / 558$ \\
\hline & AM04 & 16 & 0.202 & 44.6 & $\emptyset 16 / 16$ s125 & $0.75 \% / 0.75 \%$ & $516 / 516$ \\
\hline$B=3.00 h=0.25 d_{c}=0.166$ & PE7 & 16 & 0.213 & 42.5 & $\varnothing 20 / 20$ s100 & $1.47 \% / 1.47 \%$ & $542 / 542$ \\
\hline
\end{tabular}

straight forward manner. This Multi-level Assessment Strategy can be seen as a complement to the Level-of-Approximation-Approach introduced by MC2010 [26,27] for assessing RC slabs. Five analysis levels (I to V) with increasing levels of accuracy are presented. At level I, simplified methods are used (typically, code provisions or simplified mechanical models). At level II, the analysis is performed assuming linear elastic behaviour to be able to superimpose the effect of different loads, in order to achieve the maximum internal forces throughout the structure for all possible load combinations. The internal forces (axial forces, shear forces and flexural moments) are then compared to the corresponding resistances determined by local models for bending, shear, punching and anchorage of reinforcement. At level III, nonlinear shell finite elements are used, with the capability of reflecting the flexural strength of RC slabs directly in the FEA. However, at level III, the out-of-plane shear strength has to be determined using local resistance models. At level IV, both bending and shear type failures including punching can be reflected by performing the nonlinear analysis using 3D continuum elements coupled with fully bonded reinforcement. For this reason, at level IV, bond strength has to be verified separately. Level V is a refinement of level IV, where the bond-slip behaviour of the interface between the reinforcement and the concrete is included. With this level of accuracy in the structural analysis, no failure modes need to be checked separately using resistance models. Thus, the load carrying capacity at the structural level $\mathrm{V}$ can be determined using a one-step procedure. In order to achieve the aim of this study, level III and IV analyses were adopted.

\subsection{Shell FEA (level III)}

At level III analysis according to Plos et al. [16], nonlinear shell finite elements coupled with fully bonded reinforcement are used, with the capability of reflecting the bending behaviour of RC slabs directly in the FEA. Due to the symmetry of geometry and loading conditions, only a quarter of the slab was modelled (as an example, 


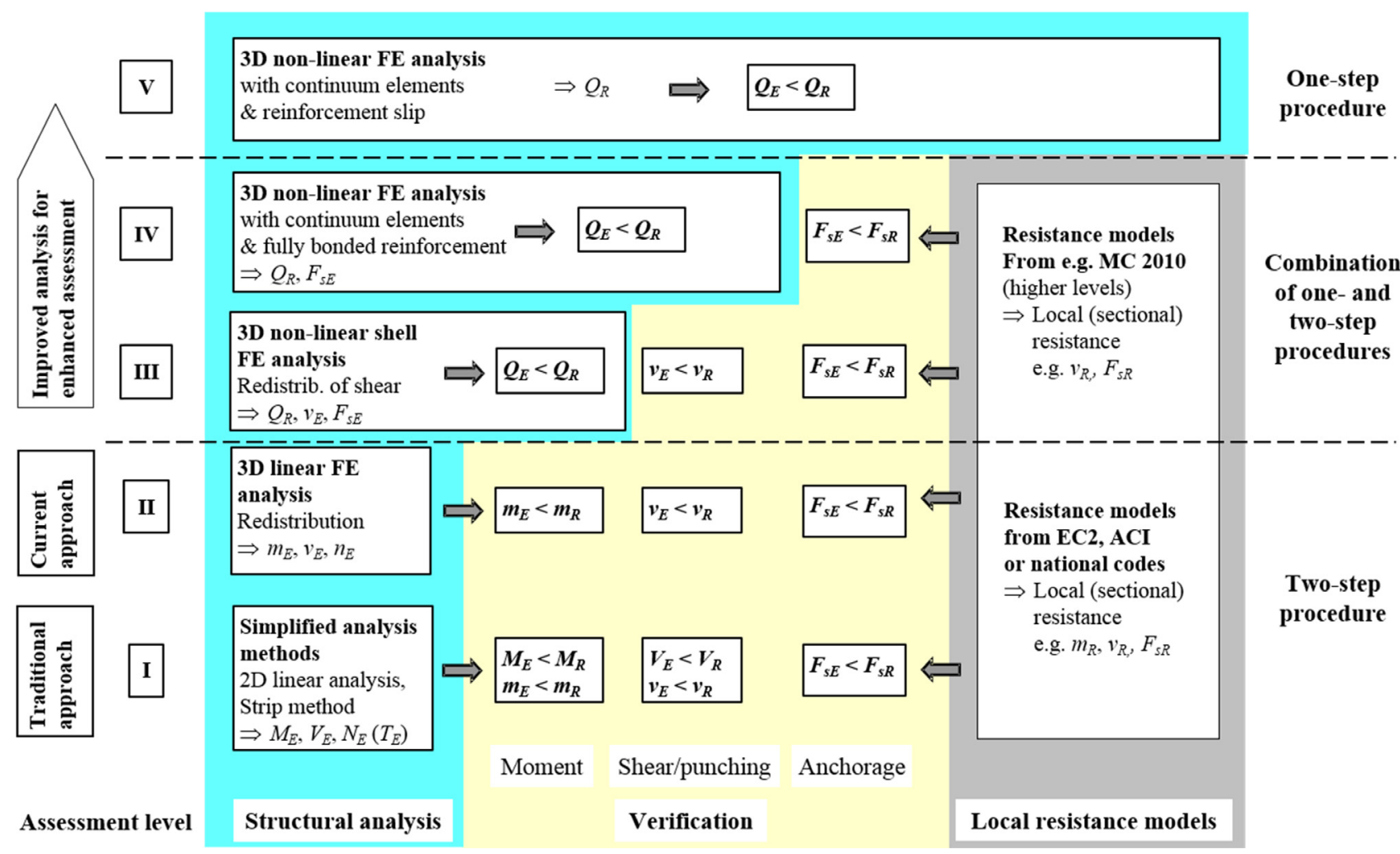

Fig. 2. Scheme of Multi-level Assessment Strategy for RC slabs, from Plos et al. [16].

the model for PG1 is presented in Fig. 3). Eight node multi-layered shell elements $(\approx 34 \mathrm{~mm} \times 34 \mathrm{~mm}$ in average $)$ accounting shear deformation with reduced integration were adopted for the reinforced concrete [15]. The slab thickness was subdivided into seven layers according to rebar setup. Three Simpson integration points were used for each layer, yielding a total of twenty-one integration points in total over the slab thickness. The vertical support provided by the columns in the centre of the slabs were modelled using nonlinear non-tension spring elements providing stiffness in compression only as described in the following section. On the symmetry faces, all displacements perpendicular to the crosssections and rotations were fixed. The column was fixed in the vertical direction.

The analyses were carried out by applying forces to eight nodes along the perimeter of the slabs according to the experimental setup. The solution was achieved using a regular Newton-Raphson iteration method based on displacement, force and energy convergence criteria. A mesh sensitivity analysis about this model made in Belletti et al. [13] indicated that this level of mesh density is of fine enough to predict the expected structural behaviour. Other parameters regarding numerical and constitutive parameters such as fracture energy and effect due to lateral cracking were also investigated and demonstrated in Belletti et al. [13].

In order to calculate punching shear strength, the Critical Shear Crack Theory (CSCT) failure criterion by Muttoni [23] was adopted in the analyses. According to this mechanical model, the punching shear strength is reduced with increasing slab rotation $\psi$ due to the increase of the width of the critical shear crack. The slab rotation $\psi$ calculated with the NLFEA can be used to determine the punching shear strength according to Equation:

$V_{R}=\frac{0.75 \cdot b_{0} \cdot d \sqrt{f_{c}}}{1+15 \cdot \psi \cdot d / d_{d g}}$

where $d$ is the effective depth; $d_{d g}$ is the maximum aggregate size $d_{g, \max }+16 \mathrm{~mm}$ and $b_{0}$ is the control perimeter at $d / 2$ from the edge of the column (according to MC2010 [3]). In order to calculate the punching shear strength using the CSCT, the intersection between the failure criterion of Eq. (2) and the load-rotation relationships obtained from the FEA needs to be determined.

\subsubsection{Material behaviour}

The crack model used for reinforced concrete is the "PARC_CL" crack model $[14,15]$, developed at the University of Parma and implemented in the ABAQUS user subroutine UMAT, according to the material properties reported in Table 1. The PARC_CL model is a constitutive model for the analysis of the nonlinear behaviour up to the failure of reinforced concrete elements. It is an extension of the crack model called Physical Approach for Reinforced Concrete (PARC) implemented for monotonic loading [13]. In the crack model at each integration point two reference systems are defined: the local $x, y$ coordinate system, and the 1,2 coordinate system along the principal stress directions. When the maximum tensile principal stress reaches the concrete tensile strength $f$, cracking starts to develop, and the 1,2 coordinate system is fixed.

The concrete behaviour is assumed to be orthotropic, both before and after cracking; softening in tension and compression, a multiaxial state of stress and the effect of aggregate interlock are taken into account. The reinforcement is modelled through a smeared approach; dowel action and tension stiffening phenomena are considered. The overall behaviour is obtained by assuming that concrete and reinforcement behave like two springs placed in parallel.

Fig. 4(a) presents the adopted concrete model. The stress-strain relationship for concrete in tension is defined as a function of its tensile strength $f_{t}$, the concrete strain at cracking $\varepsilon_{t, c r}$, the strain $\varepsilon_{t 1}$ and $\varepsilon_{t, u}$ (corresponding to residual stress equal to $0.15 f_{t}$ and 0 , respectively) and the fracture energy $G_{f}$ in tension. The stressstrain relationship is a combination of uncracked stage and cracked 
Symmetric condition:

- Translation along direction 1

- Rotation along direction 2
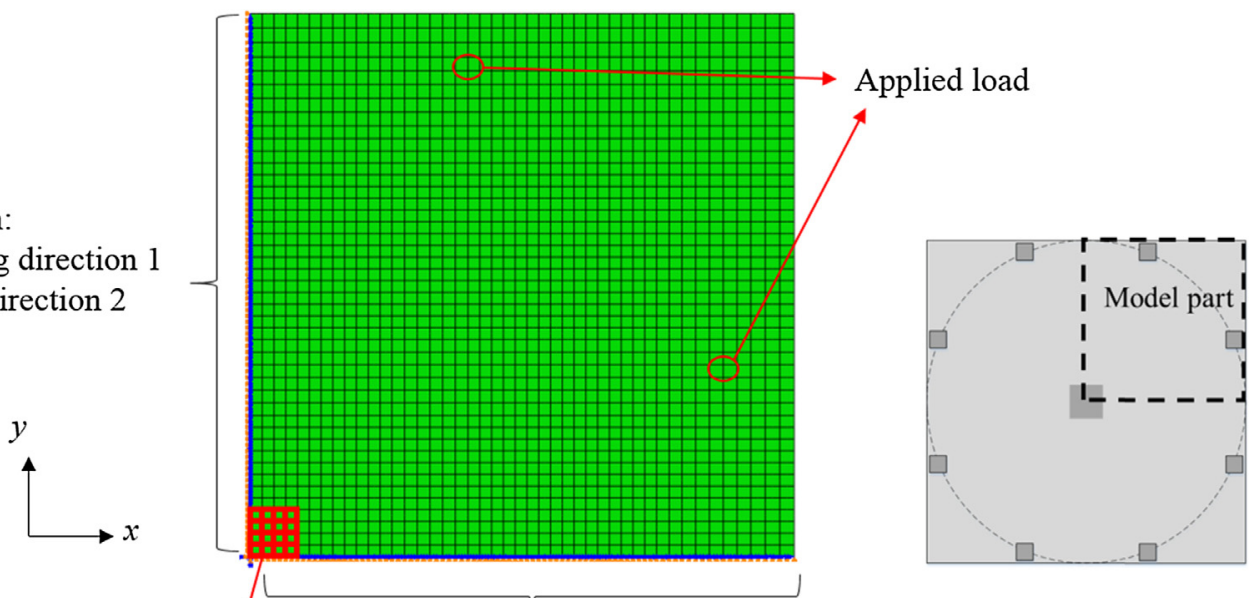

Non-tension spring

Symmetric condition:

- Translation along direction 2

- Rotation along direction 1

Fig. 3. FE shell element model of a quarter of slab PG1 in plane.
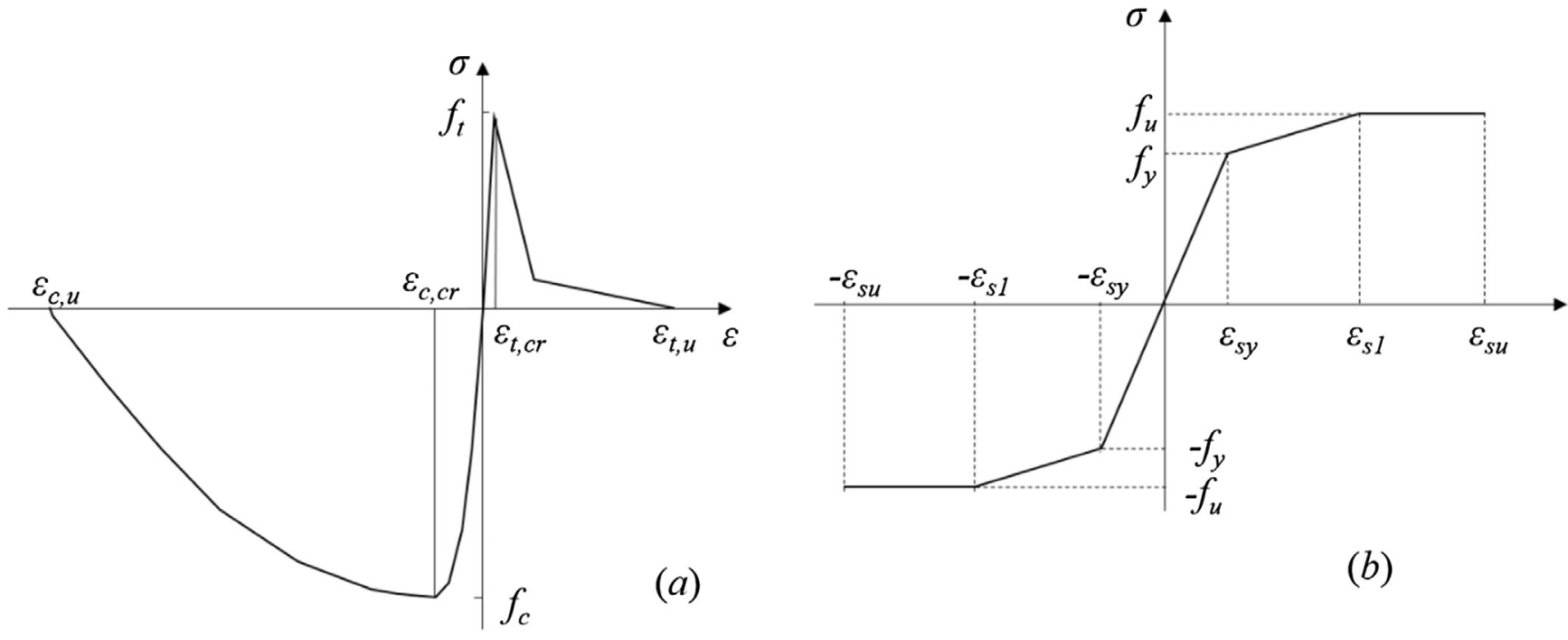

Fig. 4. Material property adopted in the shell FE model: (a) concrete and (b) reinforcing steel.

stage. The relationship at cracked stage comes from the stresscrack opening relationship, within which, the area under the stress - crack opening curve represents the energy that is consumed, or dissipated, during the fracture process. This energy is denoted the fracture energy, $G_{f}$, and is assumed to be a material parameter. The material parameters needed, in addition to the fracture energy, to describe the formation of cracks are the concrete tensile strength, $f_{t}$, and the shape of the stress - strain relationship with consideration of crack band width.

The compressive branch before reaching the peak is defined as Sargin relationship and after the peak with Feenstra relationship as a function of the concrete compressive strength $f_{c}$ and concrete fracture energy in compression, assumed equal to $250 G_{f}$, [13]. Multi-axial state of stress is considered in accordance with Vecchio and Collins [28].

The stress-strain relationship for reinforcing steel is represented by an idealized elastic-hardening plastic bilinear curve, identical in tension and compression, using values obtained from material tests; see Fig. 4(b).

\subsection{Continuum FEA (Level IV)}

According to level IV analysis in Plos et al. [16], the RC slabs were modelled using 3D brick 8-node continuum elements $(\approx 34 \mathrm{~mm} \times$ $34 \mathrm{~mm} \times 31 \mathrm{~mm}$ in average) in TNO DIANA 9.6 [29]. There are totally 8 elements in vertical directions. As an example, the FE model for PG1 is presented in Fig. 5. Boundary conditions are indicated by arrows in the directions with fixed degrees of freedom. On the symmetry faces, all displacements perpendicular to the cross-sections were fixed. The vertical support provided by the columns in the centre of the slabs were modelled using nonlinear non-tension spring elements providing stiffness in compression only as described in a following section. The column was fixed in the vertical direction. The reinforcement was modelled assuming fully bonded. The loading steel plates above the slab were included and the loads were applied to the loading plates, as in the experiments. Interface elements including a MohrCoulomb friction model were used between the concrete and steel plates and the effect of the interface element has been described in Shu et al. [21]. 


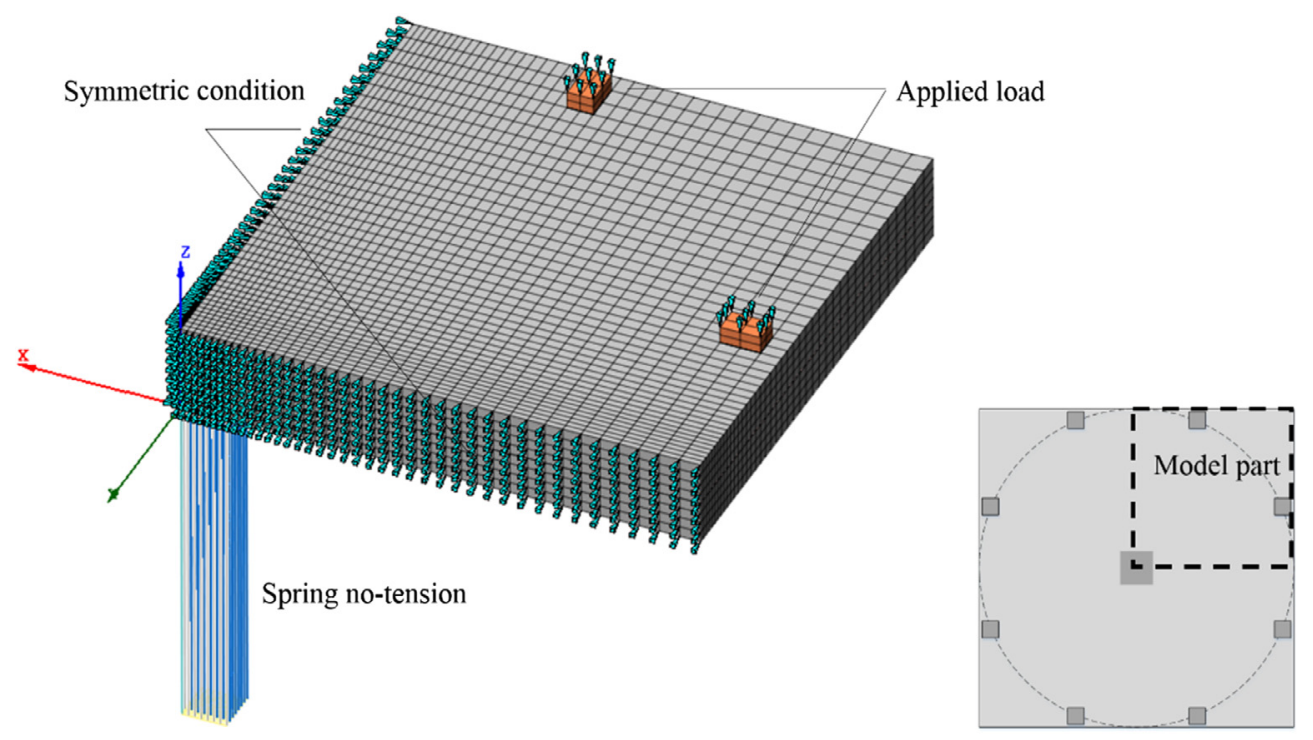

Fig. 5. FE continuum element model of a quarter of slab PG1.

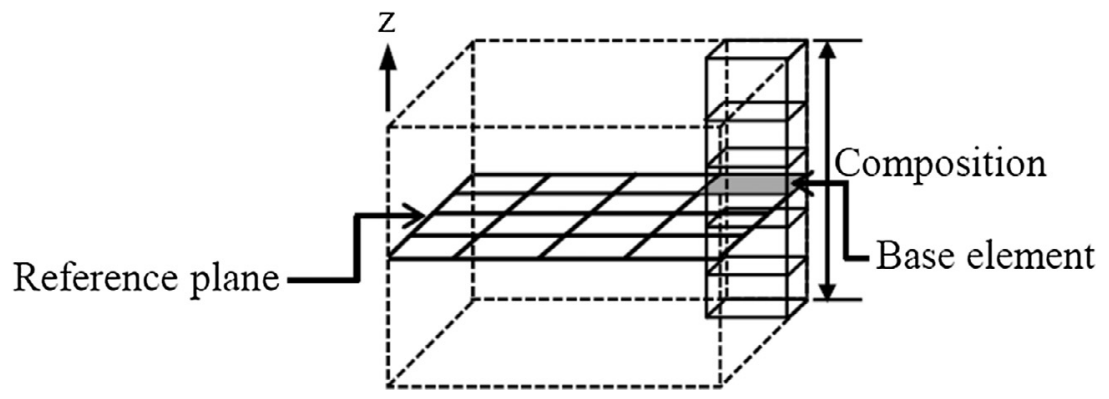

Fig. 6. Base elements in a structural composition of regular continuum elements [29].

The analyses were carried out by applying forces in eight nodes along the perimeter of the slabs according to the experimental setup. The analyses were carried out using a regular Newton-Raphson iteration method based on force and energy convergence criteria. According to the previous study [22], the mesh size has been proven to have minor impact to the analyses results when the presented modelling method is used. A sensitivity analysis about this model regarding numerical and constitutive model was conducted and described in Shu et al. [20,21].

To extract the cross-sectional forces and moments from the continuum elements after the analysis, special composed elements [29] were used, as shown in Fig. 6. Usually, if the continuum element is used, force and moment are obtained by integration of output stress. In this model, the composed elements are used for post processing of force and moment. They have no mechanical properties of their own. A composed element used for post-processing purpose is defined by a base element along with a composition of regular continuum elements. The base element layer forms a reference plane for which the generalized forces and moments are calculated by integrating shear stress in the local $z$ direction over the continuum elements connected to each base element. In this way, the force and moment can be output directly from the base elements.

\subsubsection{Material behaviour}

The crack model used for concrete is the total strain based rotating smeared crack model [29] with crack band approach, according to material parameters in Table 1 . In this approach, the crack width $w$ was related to the crack strain $\varepsilon_{c, c r}$ perpendicular to the crack via a characteristic length - the crack bandwidth $h_{b}$. The reinforcement was modelled assuming complete interaction with the surrounding concrete; consequently, the distribution of one crack would be smeared over the mean crack distance, i.e. $h_{b}=$ mean crack distance. That means the cracking will be distributed over several elements instead of localized in one, which has been verified in Shu et al. [20]. Values of mean crack distance $h_{b}$ were calculated according to Eurocode 2 [2]. The stress-strain relationship for concrete in tension and compression is similar to that used in shell FEA, as presented in Fig. 4(a). The stress-strain relationship for reinforcing steel is presented in Fig. 4(b).

The failure criterion in 3D model considering the lateral behavior was described by the four parameter Hsieh-Ting-Chen Criterion [30] involving the stress invariants $I_{1}, J_{2}$, the maximum principal stress $f_{c 1}$, and the compressive strength of concrete $f_{c}$ :

$f\left(I_{1}, J_{2}, f_{c 1}\right)=2.0108 \frac{J_{2}}{f_{c}^{2}}+0.9714 \frac{\sqrt{J_{2}}}{f_{c}}+9.1412 \frac{f_{c 1}}{f_{c}}+0.2312 \frac{I_{1}}{f_{c}}-1=0$

with the invariants defined in terms of the stress in the concrete according to:

$J_{2}=\frac{1}{6}\left(\left(\sigma_{c 1}-\sigma_{c 2}\right)^{2}+\left(\sigma_{c 2}-\sigma_{c 3}\right)^{2}+\left(\sigma_{c 3}-\sigma_{c 1}\right)^{2}\right)$

$I_{1}=\sigma_{c 1}+\sigma_{c 2}+\sigma_{c 3}$

$\sigma_{c 1}, \sigma_{c 2}, \sigma_{c 3}$ are the principal stresses of concrete and $f_{c 1}$ is the maximum concrete principal stress.

$f_{c 1}=\max \left(\sigma_{c 1}, \sigma_{c 2}, \sigma_{c 3}\right)$ 
The parameters in Eq. (3) are determined by fitting of the uniaxial tensile and compressive strength, the biaxial compressive strength, and experimental data of triaxial tests on concrete specimens.It should be noted that the crack models for concrete are different in shell and continuum FEA. Both models were previously developed and calibrated independently [13-15,20-22]. However, the different crack models show promising and similar results [13] regarding the structural behaviour of interest in this study, at both levels of analysis.3.4. Modelling of support

In the experiments, the slabs were supported in different ways; PG1 was supported by a concrete column cast together with the slab whereas the other three slabs were supported using steel plates on a stiff supporting structure.

In continuum FEA, support can be modelled in detail as in the experiment: (i) to simulate the real conditions of PG1, continuum elements were used to model the concrete column directly; (ii) to simulate the real conditions of the other three slabs, i.e. PT32, PE7 and AM04, the steel plates were included in the level IV model to support the bottom side of the concrete slab, with interface elements (allowing lifting of the slab surface from the steel plate) between the concrete slab and the steel plate; see Fig. 7. This method has been validated to be useful by Shu et al. [20].

However, both the support including concrete column and with steel plate cannot be modelled in detail in the shell FEA (level III). Instead a simplified modelling method is needed. To investigate alternative modelling methods, two different methods were investigated: (iii) the use of non-tension spring elements and (iv) a vertically restrained support area; see Fig. 7. With non-tension spring elements (iii) the varying pressure over the column support can be modelled, including the possible lifting of the slab from a part of the support area. The compressive stiffness of the springs was calculated to equal the stiffness provided by the concrete in the supporting column. With vertically restrained support area (iv), fixed boundary conditions in the vertical direction to the slab was added. This approach was studied because it would be the easiest way to model the support, even though it would not reflect the column stiffness or the possible lifting of the slab from the support.

The load-rotation relationships using the four different approaches to model the support have been compared to the test result of PG1 in Fig. 8. It shows that the analysis with (iii) non-tension spring column as well as detailed modelling of the support conditions (i) and (ii) yield similar response as the experiment. However, to model the support as fully fixed over

(i) Concrete column

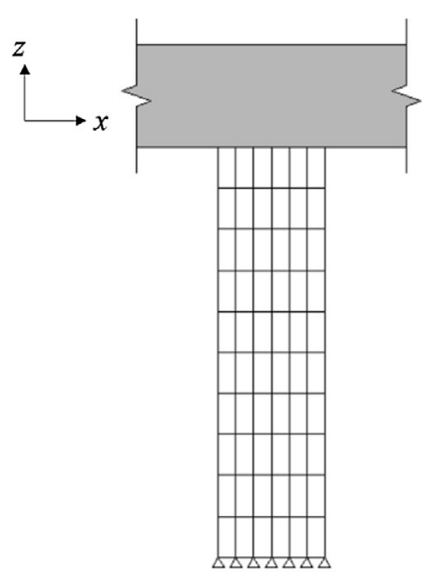

(ii) Steel plate

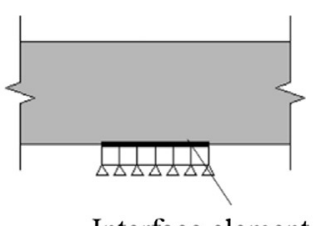

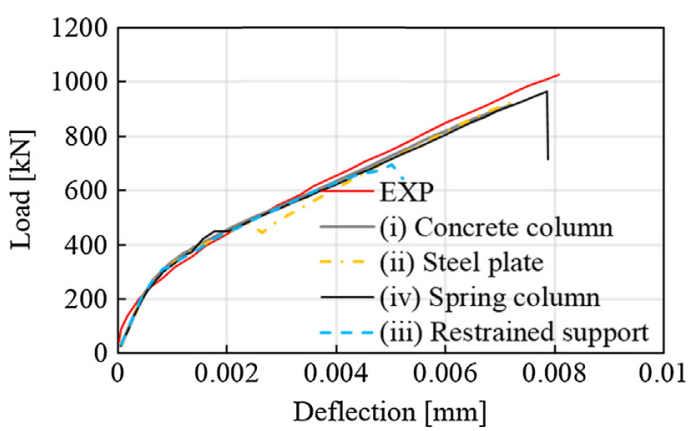

Fig. 8. Load-deflection relationships, using the four different approaches to model the support from a column, compared to the experimental response.

the entire support area leads to an underestimation of the load carrying capacity of the slab.

In Fig. 9, the principal total strain-based crack patterns in the central cross-section of the slab at different load stages are shown and compared to the failure crack pattern from the test of PG1. It indicates that the crack pattern predicted with modelling approach (iii) is similar to (i) and (ii). However, the results from modelling approach (iv) are different because the stiffness of the column support has not been modelled realistically with this method.

The investigation shows that the best approach to simplify the modelling of the support conditions for a slab supported by a column is to use non-tension spring elements, reflecting the stiffness of the column; this yields results that correspond well with test results. This approach is suitable both for shell FE models (level III) and continuum FE models (level IV).

\section{Results and discussion}

\subsection{Global structural behaviour from nonlinear FE analyses (Levels III and IV)}

The load-rotation relationships obtained from NLFEAs (level III and IV [16]) and the comparison to experiments are shown in Fig. 10. It can be observed that the stiffness of the RC slabs could be accurately reflected with both shell FEA and continuum FEA. For slabs PG1 and PE7, the rotations in $x$ and $y$ directions are almost identical. For this reason, only the rotation in $x$ direction is depicted in Fig. 10. However, for slabs PT32 and AM 04, the load (iii) Spring column

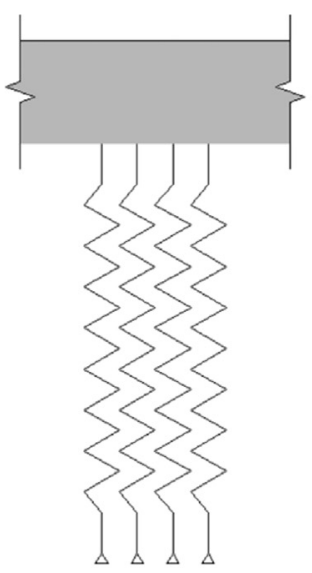

(iv) Restrained support

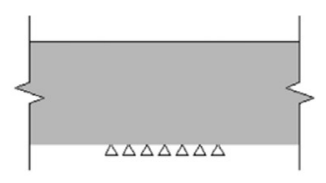

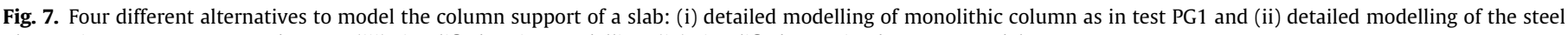
plate as in tests PT32, PE7 and AM04, (iii) simplified spring modelling, (iv) simplified restrained support model. 


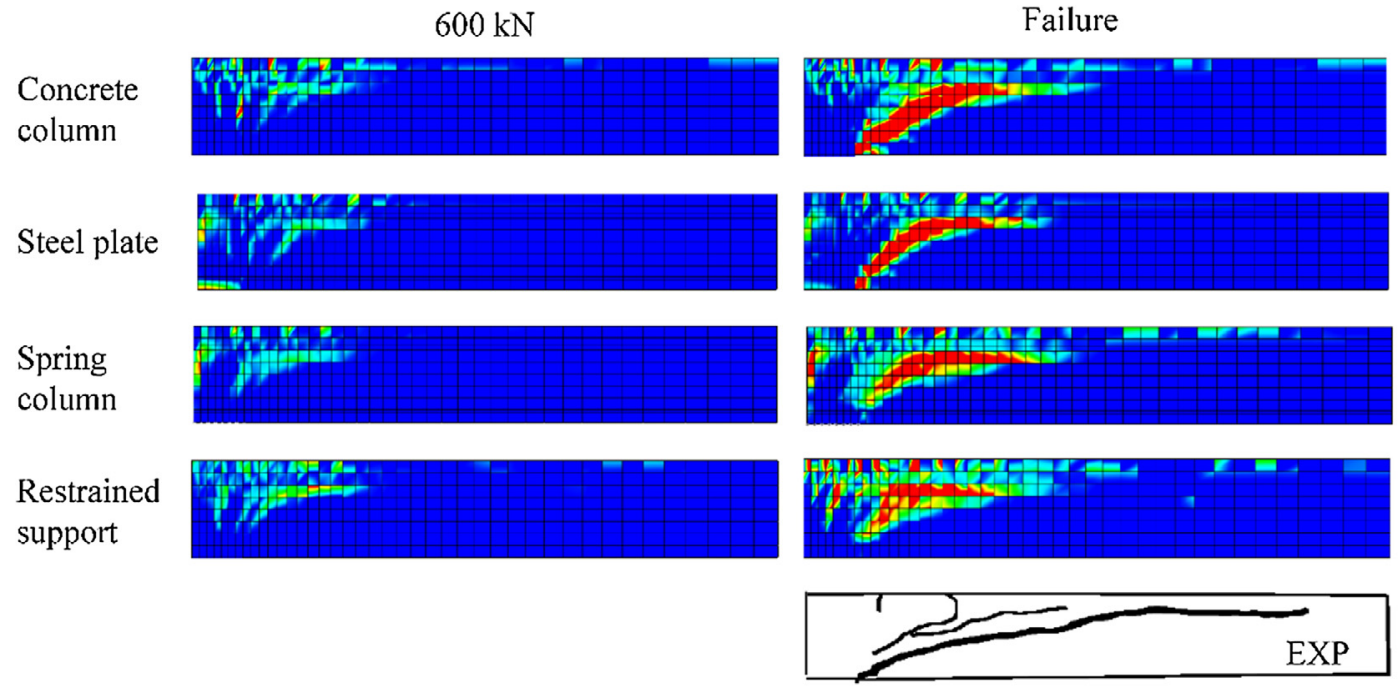

Principal Crack

total width

strain $[\mathrm{mm}]$

$6.17 \mathrm{E}-03 \quad 5.00 \mathrm{E}-01$

$5.40 \mathrm{E}-03 \quad 4.37 \mathrm{E}-01$

4.63E-03 3.75E-01

$3.86 \mathrm{E}-03 \quad 3.13 \mathrm{E}-01$

$3.09 \mathrm{E}-03 \quad 2.50 \mathrm{E}-01$

$2.31 \mathrm{E}-03 \quad 1.87 \mathrm{E}-01$

$1.54 \mathrm{E}-03 \quad 1.25 \mathrm{E}-01$

$7.71 \mathrm{E}-04 \quad 6.25 \mathrm{E}-02$

$0.00 \mathrm{E}+00 \quad 0.00 \mathrm{E}+00$

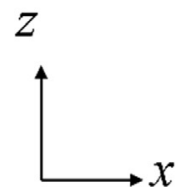

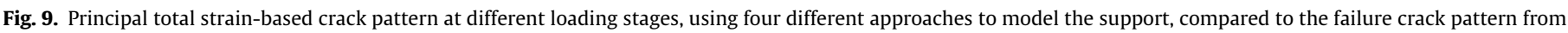
the test of PG1.

rotation curves along both $x$ and $y$ directions are slightly dissimilar because of the different layout of reinforcement or column geometry in both directions. This observation was also consistent with the results from the two-way slab experiments by Fall et al. [31].

By using multi-layered shell elements and the PARC_CL crack model [14], the punching shear strength was determined at the intersection between the failure criterion of Eq. (2) and the loadrotation relationships from the shell FE analyses (Fig. 10). At level IV, the punching shear strength was determined when the contin-
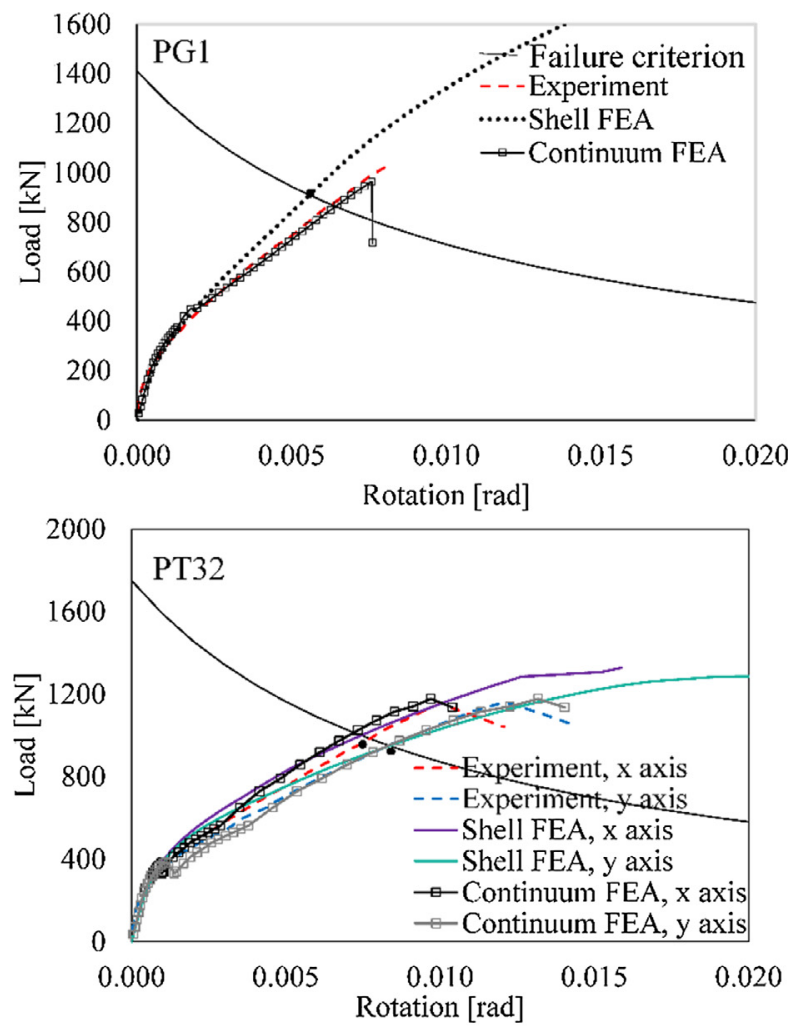

uum FE model failed in the FE analyses due to crushing of the compression elements. The shear strength determined through the nonlinear FEAs with shell and continuum elements, respectively, and that calculated based on EC2 [2] (level I according to Plos et al. [16]) are compared to the experimental results in Table 2 and Fig. 11. It is observed that all three methods can be used to calculate the punching shear strength with reasonable accuracy. It is also observed that for the investigated tests, already Level I (EC2 [2]) provides accurate results. This is not surprising as the empirical
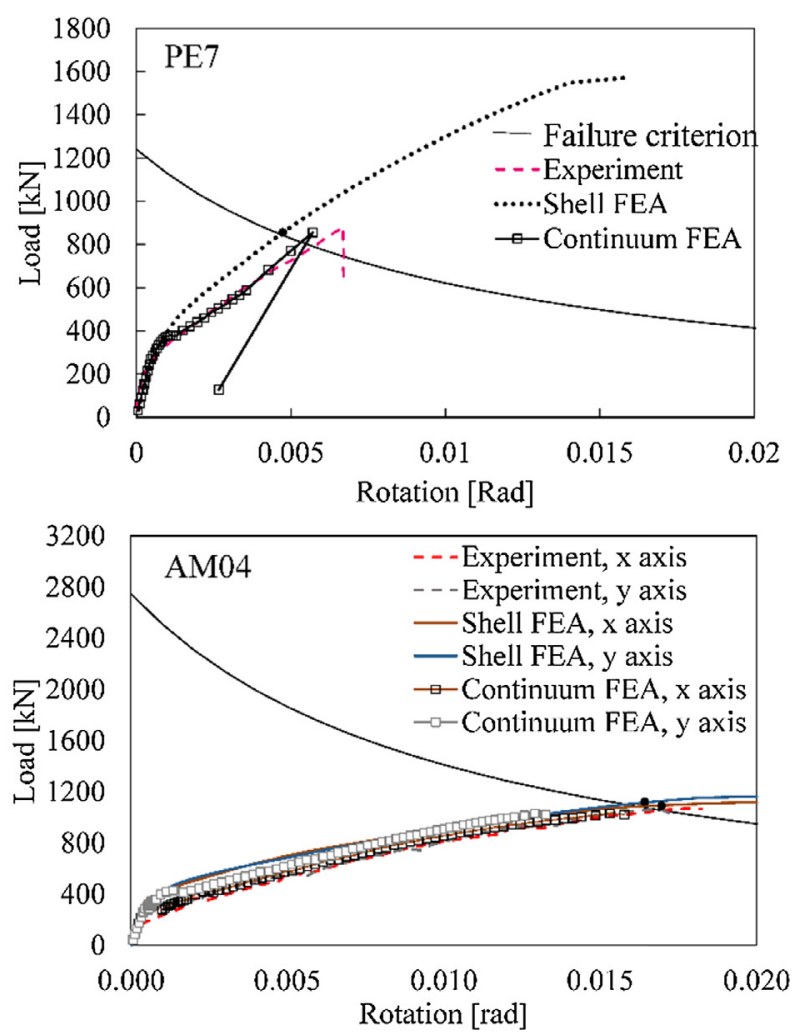

Fig. 10. The load-rotation relationships obtained from nonlinear shell FEA, CSCT failure criterion, continuum FEA and the comparison to experiment. 
Table 2

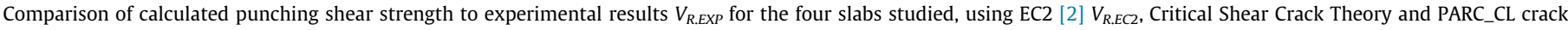
model $V_{R \text {.shell }}[23]$ and nonlinear continuum FEA $V_{R \text {.cont }}$.

\begin{tabular}{|c|c|c|c|c|c|c|c|}
\hline Specimens & $V_{R . E X P}[\mathrm{kN}]$ & $V_{R . E C 2}[\mathrm{kN}]$ & $V_{\text {R.shell }}[\mathrm{kN}]$ & $V_{\text {R.cont. }}[\mathrm{kN}]$ & $V_{R . E X P} / V_{R . E C 2}$ & $V_{\text {R.EXP }} / V_{\text {R.shell }}$ & $V_{\text {R.EXP }} / V_{\text {R.cont. }}$ \\
\hline PG1 & 1023 & 950 & 932 & 964 & 1.08 & 1.10 & 1.06 \\
\hline PE7 & 871 & 937 & 866 & 854 & 0.93 & 1.01 & 1.02 \\
\hline РT32 & 1157 & 989 & 957 & 1177 & 1.17 & 1.21 & 0.98 \\
\hline AM04 & 1067 & 1111 & 1057 & 1029 & 0.96 & 1.01 & 1.04 \\
\hline \multicolumn{5}{|l|}{ Average } & 1.03 & 1.08 & 1.03 \\
\hline \multicolumn{5}{|c|}{ Coefficient of variation } & 0.09 & 0.08 & 0.03 \\
\hline
\end{tabular}

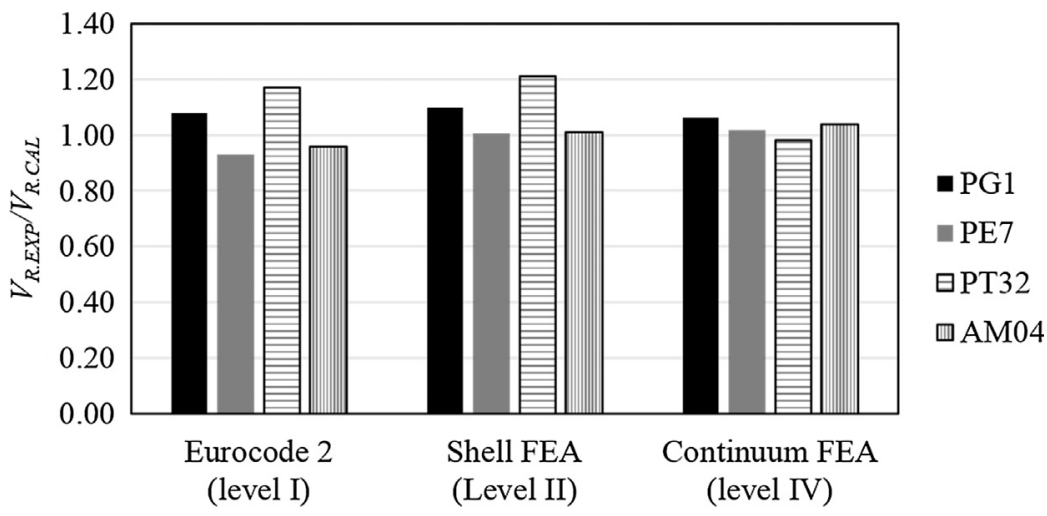

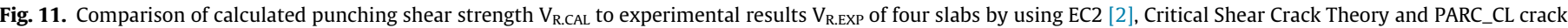
model (shell FEA) [23] and nonlinear continuum FEA.

Equation of EC2 [2] has been calibrated on tests which cover similar parameters [32] as the tests described in this work. The advantage of Levels III and IV is that almost all actual practical cases with different geometries, reinforcement arrangements, support types and loading types can be investigated in a consistent manner. The advantage of using building code provisions (level I) or mechanical models (e.g. [24]) is that more robust calculations are possible.

The principal total strain-based crack patterns of half a crosssection, predicted by the continuum FE model at level IV are displayed and compared to the experimental crack pattern in Fig. 12.
It is noted that the failure shear crack can be reflected with reasonable accuracy for all four slabs. In the tests of Sagaseta et al. [6] and Guandalini et al. [33], flatter inclination of the failure crack have been observed for larger flexural reinforcement ratios. This is observed in the experimental crack pattern for the two different directions $x$ and $y$ of PT32. This phenomenon is also observed in the FEA, but not as evident as in the experiment.

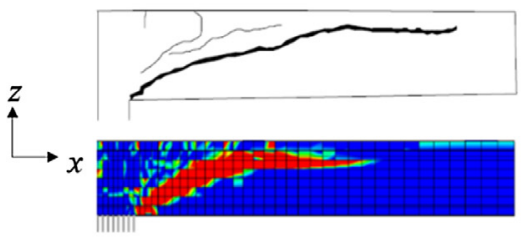

PG1

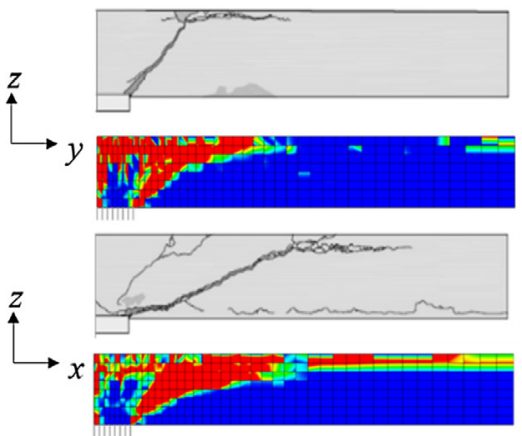

PT32

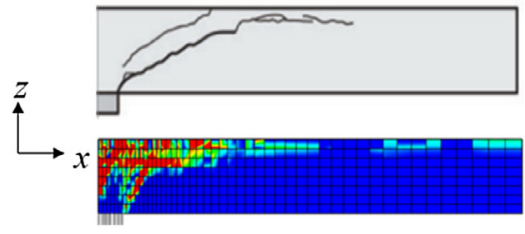

PE7

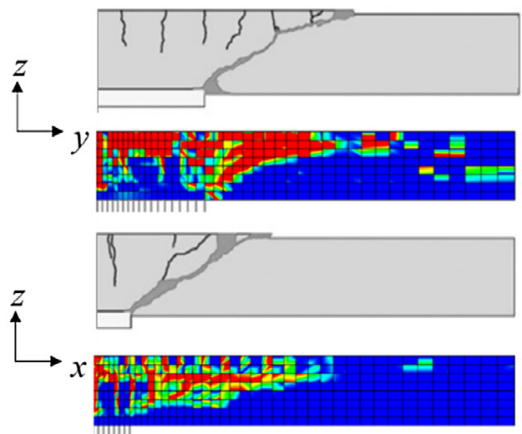

AM04

$\begin{array}{ll}\begin{array}{l}\text { Principal } \\ \text { total }\end{array} & \begin{array}{l}\text { Crack } \\ \text { width } \\ \text { strain } \\ {[\mathrm{mm}]}\end{array} \\ 6.17 \mathrm{E}-03 & 5.00 \mathrm{E}-01 \\ 5.40 \mathrm{E}-03 & 4.37 \mathrm{E}-01 \\ 4.63 \mathrm{E}-03 & 3.75 \mathrm{E}-01 \\ 3.86 \mathrm{E}-03 & 3.13 \mathrm{E}-01 \\ 3.09 \mathrm{E}-03 & 2.50 \mathrm{E}-01 \\ 2.31 \mathrm{E}-03 & 1.87 \mathrm{E}-01 \\ 1.54 \mathrm{E}-03 & 1.25 \mathrm{E}-01 \\ 7.71 \mathrm{E}-04 & 6.25 \mathrm{E}-02 \\ 0.00 \mathrm{E}+00 & 0.00 \mathrm{E}+00\end{array}$

Fig. 12. Principal total strain-based crack pattern of half a cross-section of slabs after failure, obtained from continuum FEA and the comparison to experiment. 
Control perimeter, output of shear force

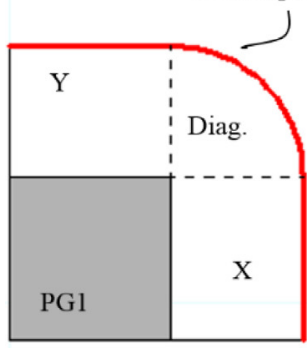

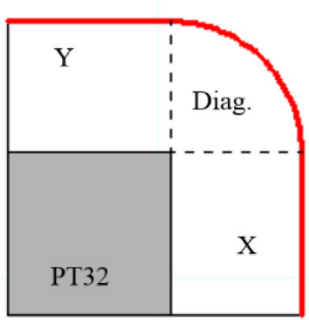

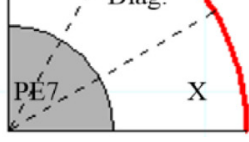

Fig. 13. Control perimeters for output of the shear force in the slabs.
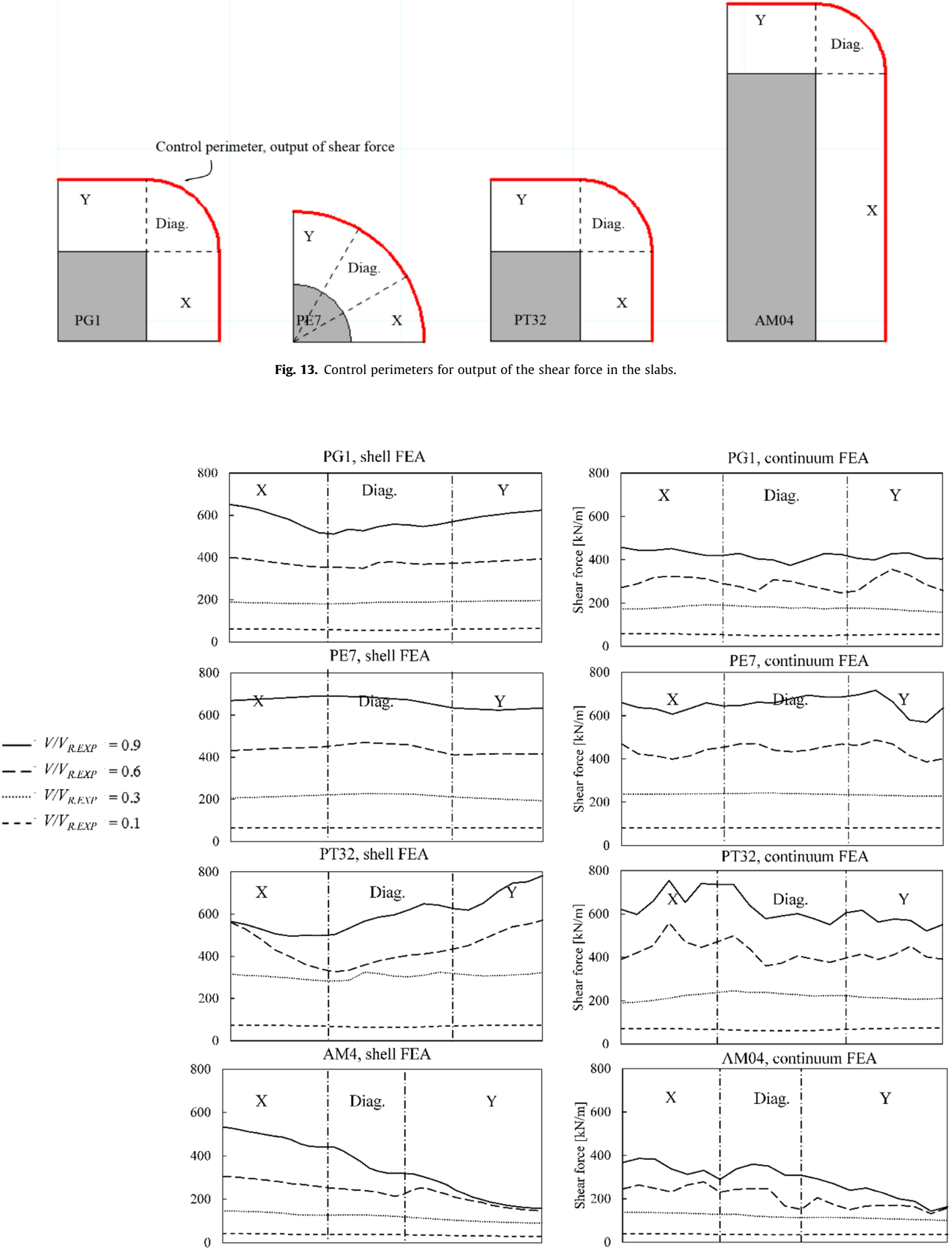

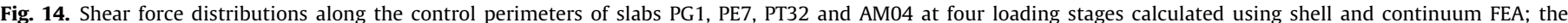
abscissas show the distance along the control perimeter (red lines in Fig. 13); the ordinates show shear force per unit length [kN/m]. 
4.2. Shear force distributions and redistributions from nonlinear FE analyses (Levels III and IV)

The most important objective of this study is to investigate the shear force distributions around the column. The shear force was calculated along a control perimeter around the column at a dis-
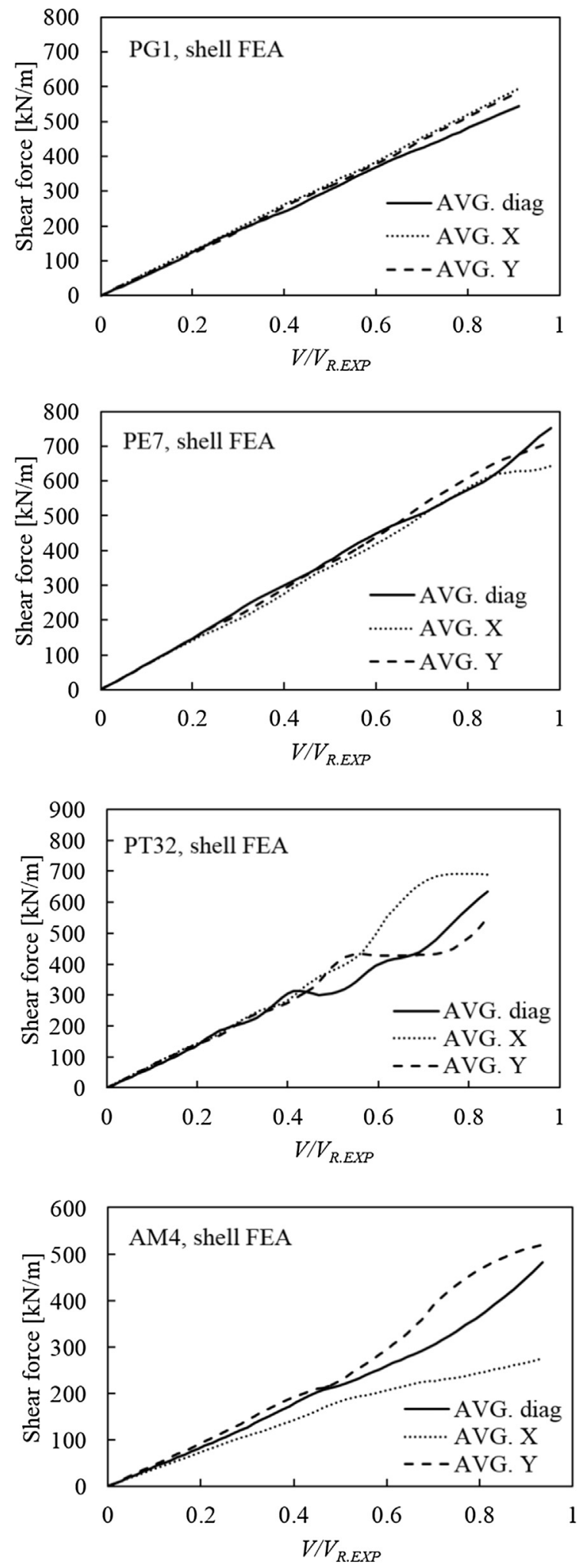

tance of $\mathrm{d} / 2$ from the column face. The studied control perimeter for a quarter of each slab (see Fig. 13) can be divided into three different regions: regions $\mathrm{X}, \mathrm{Y}$ and the Diagonal region.

The shear force distributions along the control perimeter at different loading stages $\left(V / V_{R . E X P}\right)$ of slabs PG1, PE7, PT32 and AM04 from the shell and continuum FEAs are presented in Fig. 14. The
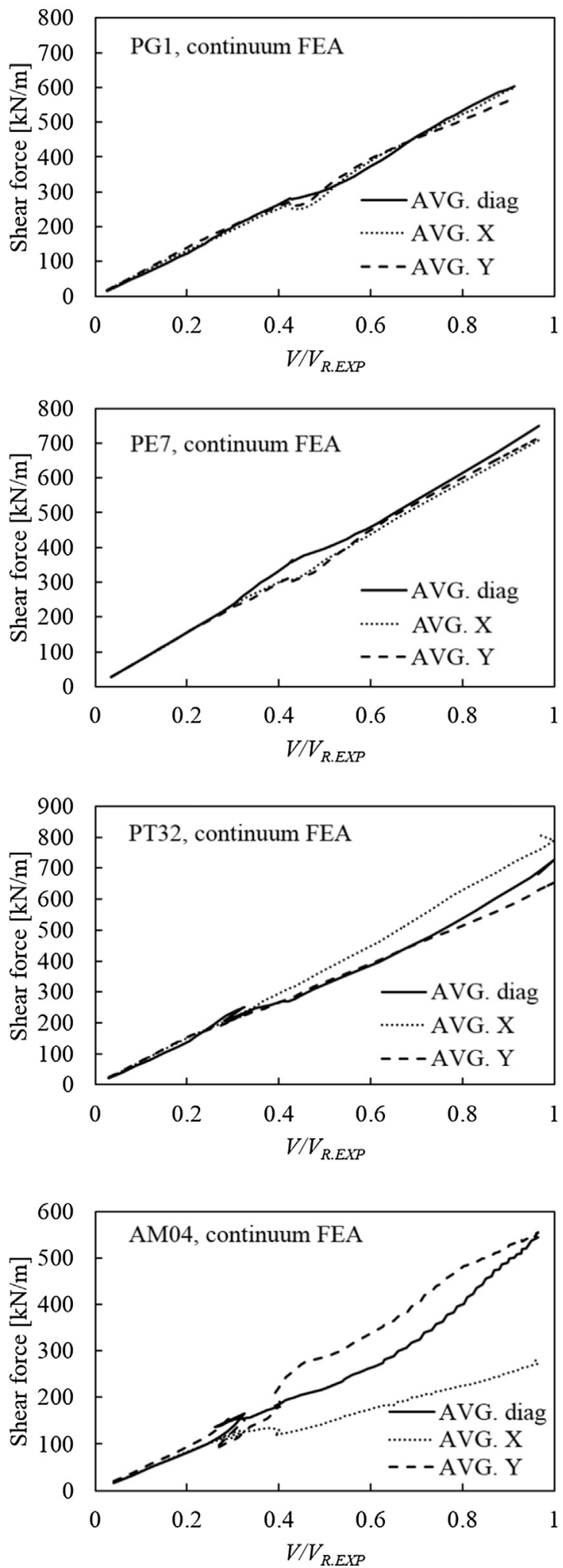

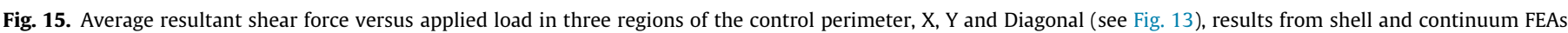


abscissa describes the distance along the control perimeter (the red line in Fig. 13) whereas the ordinate shows the shear force per unit length $[\mathrm{kN} / \mathrm{m}]$. By comparing different load stages for all slabs, it becomes evident that at lower load levels, i.e. $V / V_{R . E X P}=0.1$ and 0.3 , the shear force distributes slightly unevenly along the control perimeter, with only minor variation. At higher loading stages, i.e. $V / V_{R . E X P}=0.6$ and 0.9 , the shear force distributions greatly fluctuate due to the formation of cracks. By comparing the different slabs, whereas the shear force of PE7 distributes evenly both in the shell FEA and in the continuum FEA because of the circular column, the shear force of AM04 is considerably higher in region Y compared to region $\mathrm{X}$ due to the rectangularly shaped column.

In order to investigate the shear force distributions and redistributions in the main directions of the slabs, the shear force along the control perimeter in the $\mathrm{X}, \mathrm{Y}$ and Diagonal regions have been averaged and the magnitude versus applied load are depicted in Fig. 15. The results show that all studied factors, i.e. the geometry of the slab, the geometry of the column and the layout of the reinforcement, have significant influences on the shear force distributions. These effects can be reflected in both shell FEA and continuum FEA. As described by Sagaseta et al. [5], in case of rectangular columns (see test AM04), the shear force concentrates in the region of the short side.

By comparing the shell FEA of PT32 to PG1 in Fig. 15, it is observed that the shear force redistributed between the main directions ( $\mathrm{X}$ and $\mathrm{Y}$ ) at load level $V / V_{R . E X P} \approx 0.5$ for PT32. The magnitude of the average shear force increases more slowly in the $Y$ region and faster in the $\mathrm{X}$ region. The reason was that the yielding of reinforcement occurred in the weaker $y$ direction at this load level.
However, in continuum FEA, the same phenomenon is not observed when comparing PT32 to PG1. The average shear force in the $\mathrm{X}$ region increased faster than in the $\mathrm{Y}$ region after development of the critical shear crack but the clear redistribution does not occur. This observation has been further investigated and the reason is found to be the formation of the critical shear crack, which cannot be reflected in the shell FE analyses. In Fig. 15, the redistribution of shear force cannot be observed for the continuum FEA because the shear force has been output along the control perimeter, located within the area where the shear cracks formed. However, the shear force outside the critical shear crack is influenced significantly by formation of the critical shear crack; see Fig. 16. The average shear force along the elements just outside the critical shear crack (blue line), for continuum FEA of slab PG1 and PT 32 are plotted versus the applied load. It is clearly illustrated that the average shear force increased only slowly due the formation of critical shear cracks (at the load level of $V / V_{R . E X P} \approx$ 0.50 for PG1 and $V / V_{R . E X P} \approx 0.46$ for PT32). However, the redistribution is clearly affected when yielding of reinforcement occurred in PT32: the average shear force increased slowly in the Y region but faster in the $\mathrm{X}$ region.

\subsection{Comparison between measured and calculated concrete strains}

As already observed by Kinnunen and Nylander [34], the radial compressive strains at the soffit of the slab near the column, after reaching a maximum for a certain load level, usually begin to decrease. In some cases, shortly before punching, tensile strains may be observed. This phenomenon has been investigated for slab PT32 using both shell and continuum FEAs and compared to the
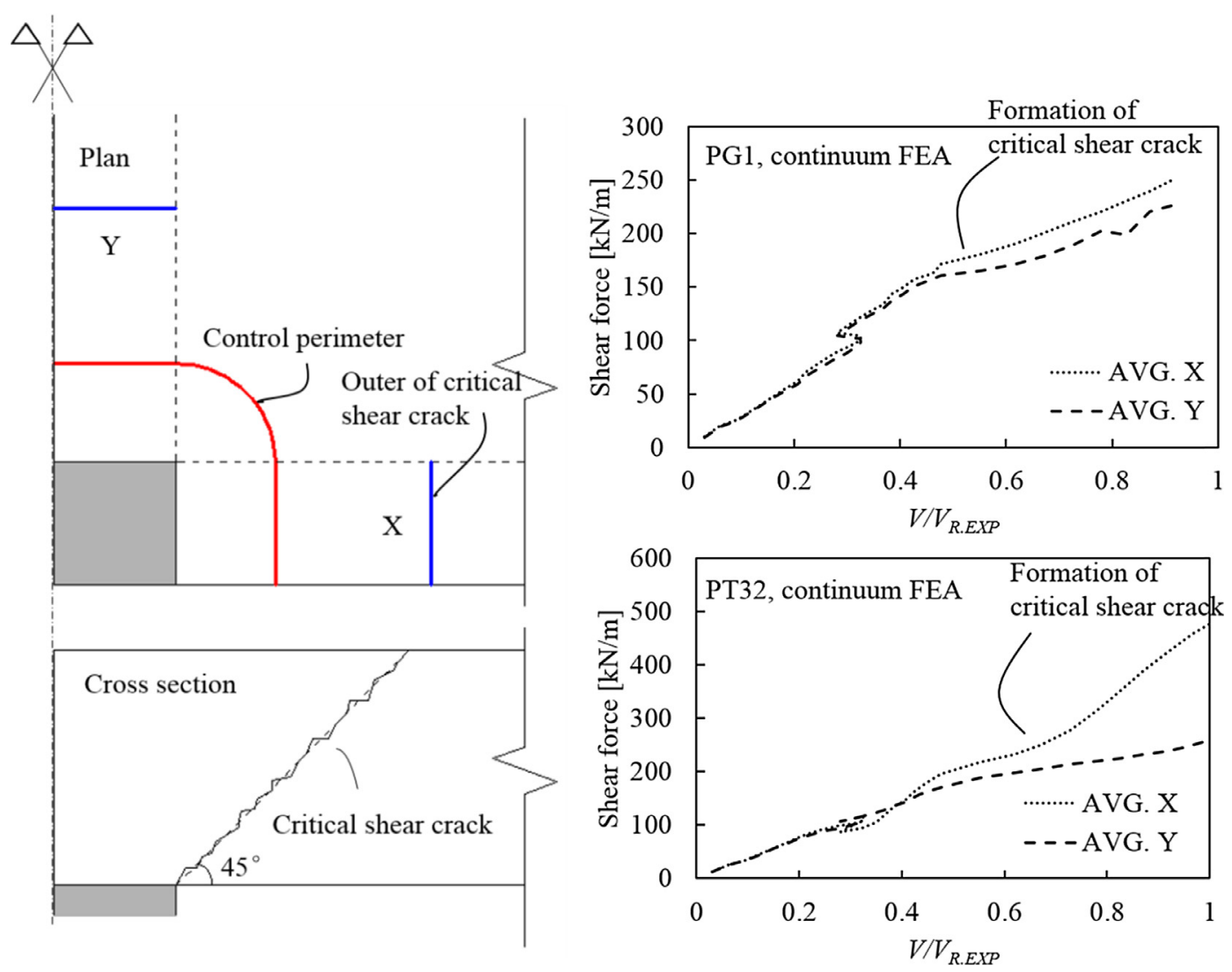

Fig. 16. Average shear force variation, just outside of the critical shear crack, versus applied load in X and Y regions in the continuum FEA of slabs PG1 and PT32. 
measurements. Fig. 17 shows the evolution of radial and tangential strains at different distances from the column. The strains increase both in radial and tangential directions initially. However, when $V /$ $V_{R . E X P} \approx 0.7$, the radial strains reach a peak and start to decrease. The deformed mesh depicted in Fig. 18 shows that this phenomenon may be explained by the shear strains associated to the development of the critical shear cracks in the column region. Nevertheless, a similar phenomenon has been captured also by the shell FEA where constant shear stiffness has been assumed and no shear strain localization at the bottom of the slab near the column is considered. For this reason, the observed phenomenon of decreasing radial strains may be explained also by relative changes of flexural stiffness in both directions.

\subsection{Effective control perimeter}

The length of effective control perimeter has been calculated for all four slabs according to Eq. (1) and the results are presented in Table 3. $b_{0, F E A}$ is the length of the effective control perimeter based on the shear force distributions in shell and continuum FEAs, and $b_{0}$ is the length of the basic control perimeter according to MC2010 (located at $d / 2$ from the column edge). A reduction factor
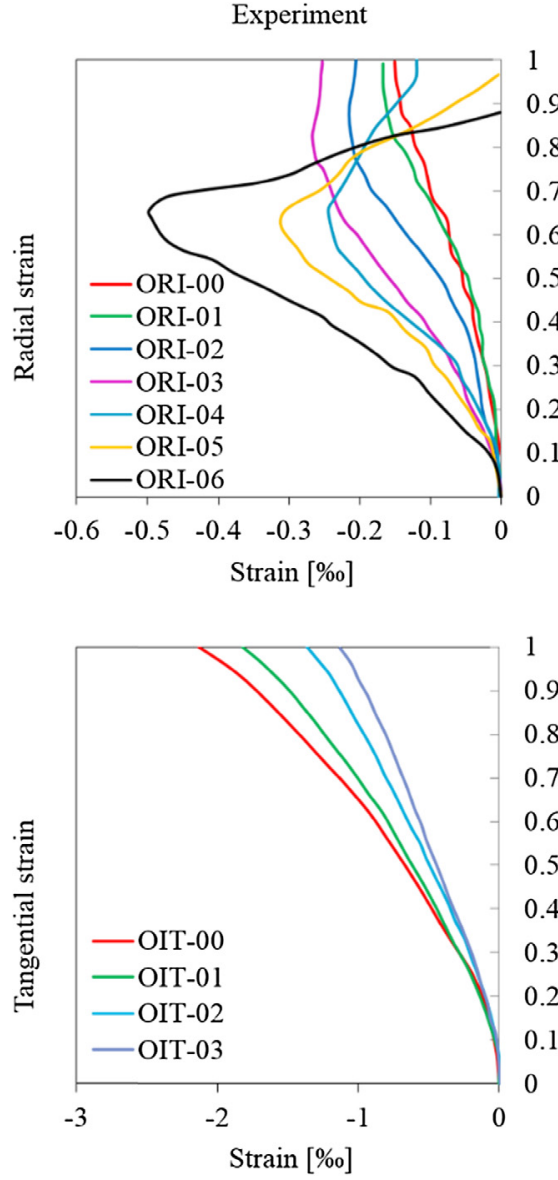

Shell FEA

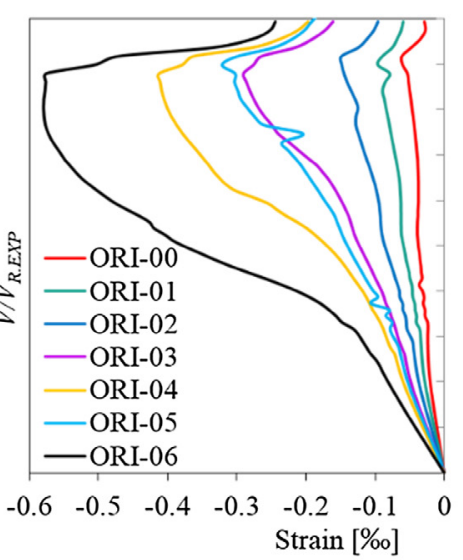

1

0.9

0.8

0.7

0.6

0.5

0.4

0.3

0.2

0.1

0
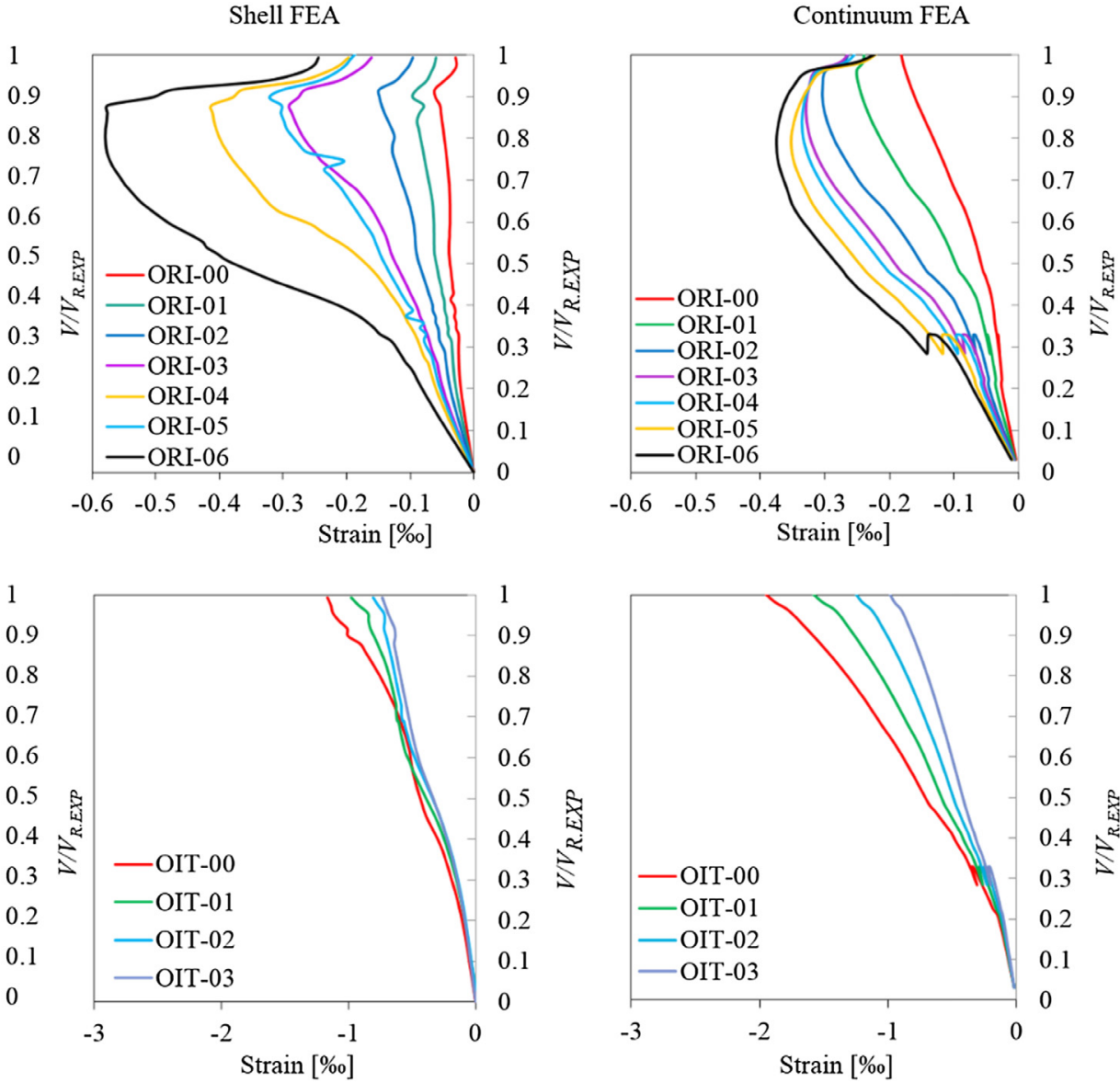

1

0.9

0.8

0.7

0.6

0.5

0.4

0.3

0.2

0.1
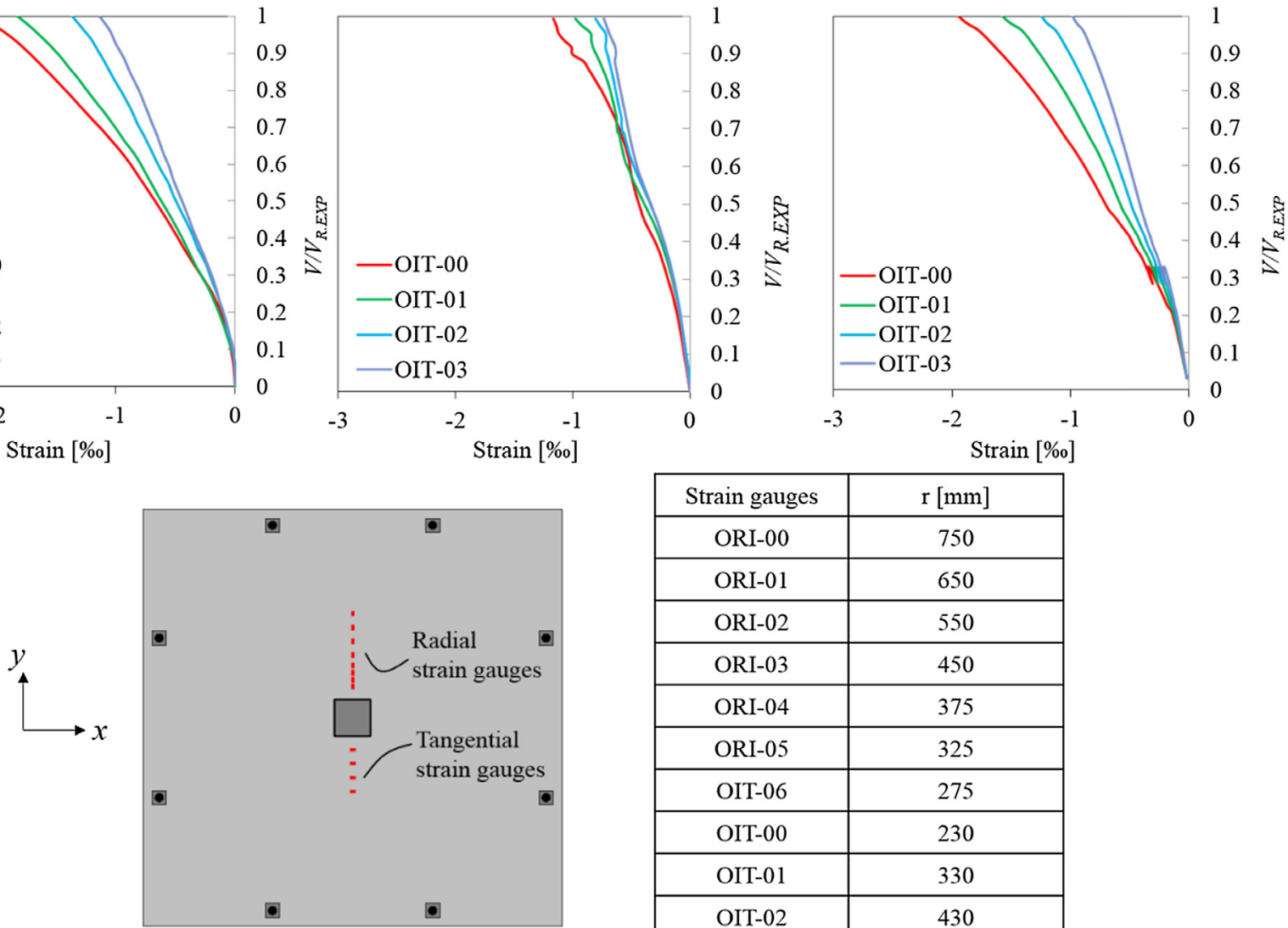

\begin{tabular}{|c|c|}
\hline Strain gauges & $\mathbf{r}[\mathrm{mm}]$ \\
\hline ORI-00 & 750 \\
\hline ORI-01 & 650 \\
\hline ORI-02 & 550 \\
\hline ORI-03 & 450 \\
\hline ORI-04 & 375 \\
\hline ORI-05 & 325 \\
\hline OIT-06 & 275 \\
\hline OIT-00 & 230 \\
\hline OIT-01 & 330 \\
\hline OIT-02 & 430 \\
\hline OIT-03 & 530 \\
\hline
\end{tabular}

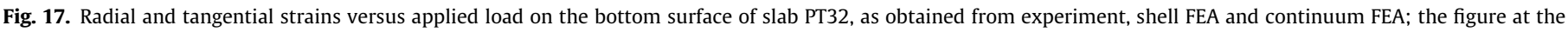
bottom indicates the positions where strains were measured; $r=$ distance of strain gauges to the centre of slab. 


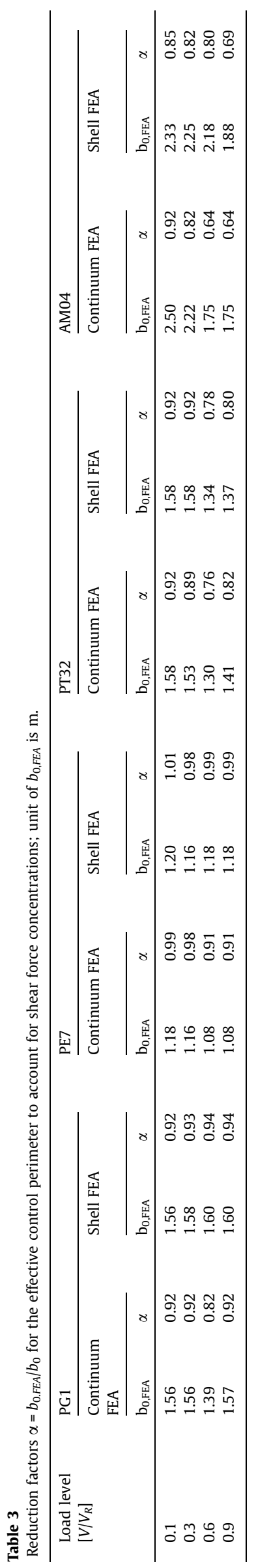

$\alpha=b_{\text {OFEA }} / b_{0}$ has also been calculated for all slabs and the results are displayed in Fig. 19. This reduction factor $\alpha$, which affects the effective control perimeter and thus the punching shear strength, is partly associated to the reciprocal of coefficient $\beta$ according to EC2 [2] which is used to increase the acting shear force. It has to be noted that the reduction factor $\alpha$ is implicitly accounted for in building codes of practice whose provisions have been calibrated on punching shear tests with square and circular columns accounting for the basic control perimeter. This means that the reduction of the effective control perimeter due to uneven shear distribution is implicitly accounted for, at least partially, in the calibration of the code provisions which has been performed on the basis of similar tests.

By comparing different slabs, PE 7 has highest reduction factor because the shear force is distributed equally along the control perimeter. PG1 and PT32 have lower reduction factor due to the shear stress concentration caused by the geometry of the square column and the non-symmetrical reinforcement. The slab with rectangular column (AM04) shows the lowest reduction factor due to the geometry of the column $\left(c_{\max } / c_{\min }=3\right)$. By comparing the reduction factors at different loading stages, in general, the reduction factors obtained in the nonlinear stage is lower than that in the elastic stage because of shear force concentrations due to increased slab curvatures over the stiff supports.

\section{Summary and conclusions}

In this paper, the behaviour of RC slabs without shear reinforcement subjected to punching failure was investigated by carrying out nonlinear finite element analyses (NLFEA) at level III and IV, according to the Multi-level Assessment Strategy. Four different types of punching tests were investigated, including the variation of reinforcement layout as well as the geometry of the slab and the column. The global behaviour and shear force distribution of these slabs in the linear and nonlinear stages were analysed. The main conclusions are:

- An appropriate approach to model the column support is to use non-tension springs in both the shell element models and the continuum element models (solid finite elements). This approach is capable of reflecting the reaction force of the column support realistically.

- The global structural behaviour of RC slabs can be reflected accurately using NLFEA, with both the shell element models and the continuum element models. The load carrying capacity can be predicted with high accuracy and small scatter.

- The advantage of NLFEA is that almost all actual practical cases with different geometries, reinforcement arrangements, support types and loading arrangements can be investigated in a consistent manner. The advantage of simplified approaches according to codes of practice or mechanical models is related to the robustness of the assessment.

- Investigations using continuum NLFEA allow very refined results in terms of local (shear force values, material strains, etc.) and global response (rotations, deflections, etc.).

- Shell NLFEA with PARC_CL crack model and CSCT failure criterion, provided also good results. This outcome is very important because shell elements modelling requires lower computational efforts and analysis time than continuum modelling. In addition, the former approach is sufficiently robust as the NLFEA is used only for investigating the flexural behaviour and the shear strength is assessed on the bases of a mechanical model.

- The shear force redistribution can be reflected consistently by NLFEA (both shell and continuum approach). 


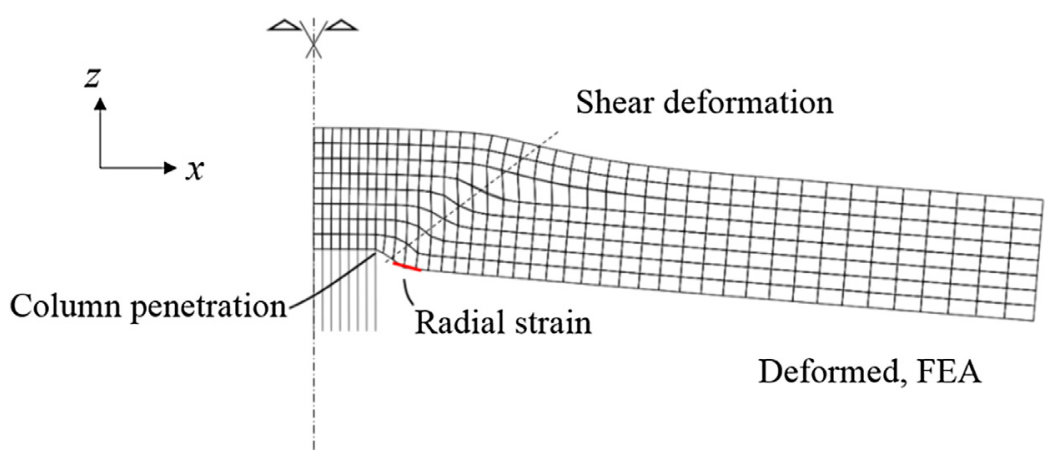

Fig. 18. Shear deformation of slab PT32 according to the Continuum FEA.
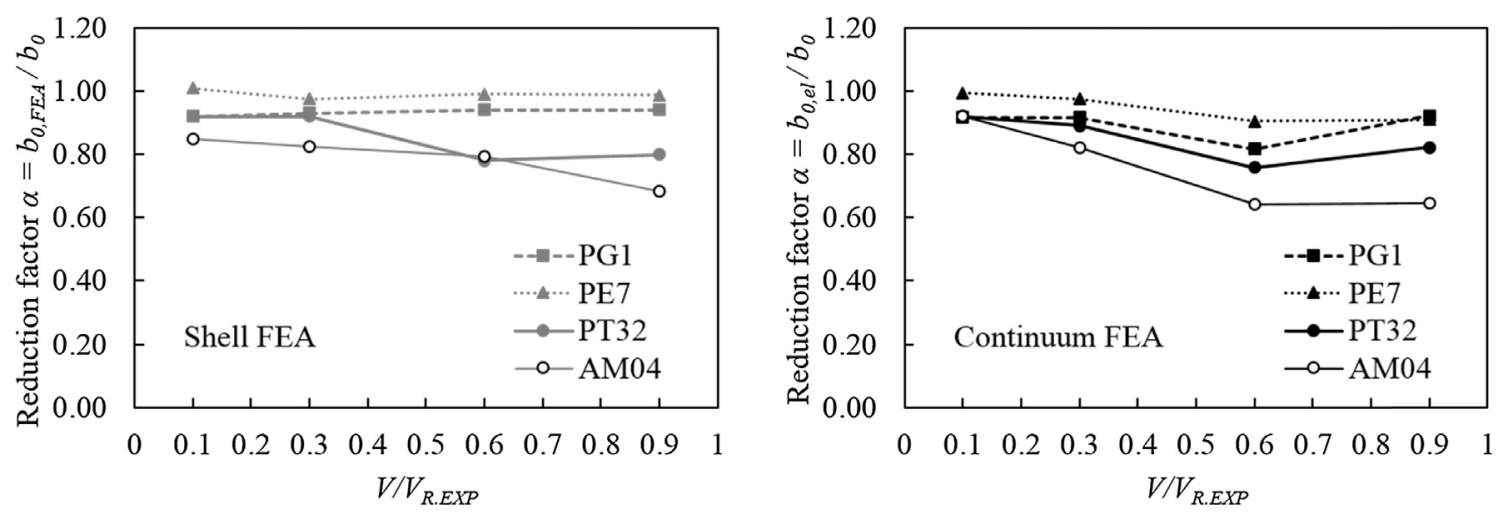

Fig. 19. Reduction factors $\alpha=b_{0 . F E A} / b_{0}$ at different load levels obtained from shell and continuum FEAs.

- Results show that the shear distribution accounting for cracking and nonlinear material behaviour shows a significant difference compared to that at linear elastic stage (corresponding to low applied load value). Thus, reinforcement arrangement also influences the shear force distribution.

\section{Acknowledgements}

The authors would like to gratefully acknowledge the support and funding from the Swedish Transport Administration (Trafikverket), which made part of the research possible.

\section{References}

[1] ACI. Building code requirements for structural concrete and commentary. Farmington Hills, Mich: ACI American Concrete Institute; 2014.

[2] CEN. Eurocode 2: design of concrete structures - part 1-1: general rules and rules for buildings. Brussels, Belgium: CEN European Committee for Standardization; 2004.

[3] Fib. Model code for concrete structures 2010. Lausanne: International Federation for Structural Concrete (fib); 2013.

[4] Vaz Rodrigues R, Fernández Ruiz M, Muttoni A. Shear strength of R/C bridge cantilever slabs. Eng Struct 2008;30:3024-33 . no. 11.

[5] Sagaseta J, Tassinari L, Ruiz MF, Muttoni A. Punching of flat slabs supported on rectangular columns. Eng Struct 2014;77:17-33.

[6] Sagaseta J, Ruiz MF, Muttoni A, Tassinari L. Non-axis-symmetrical punching shear around internal columns of RC slabs without transverse reinforcement. Mag Concr Res 2011;63(6):441-57.

[7] Fib. Bulletin No. 12: punching of structural concrete slabs. Lausanne: International Federation for Structural Concrete (fib); 2001.

[8] Menétrey P, Walther R, Zimmermann T, Willam KJ, Regan PE. Simulation of punching failure in reinforced-concrete structures. J Struct Eng 1997;123 (5):652-9.

[9] Hallgren M. Punching shear capacity of reinforced high-strength concrete slabs. Doctoral Thesis, Royal Institute of Technology in Stockholm (KTH), Stockholm; 1996.
[10] Polak MA. Shell finite element analysis of RC plates supported on columns for punching shear and flexure. Eng Comput 2005;22(4):409-28.

[11] Belletti B, Pimentel M, Scolari M, Walraven JC. Safety assessment of punching shear failure according to the level of approximation approach. Struct Concr 2015;16(3):366-80.

[12] Belletti B, Walraven JC, Trapani F. Evaluation of compressive membrane action effects on punching shear resistance of reinforced concrete slabs. Eng Struct 2015;95:25-39.

[13] Belletti B, Damoni C, Hendriks M, de Boer A. Analytical and numerica evaluation of the design shear resistance of reinforced concrete slabs. Struct Concr 2014:317-30.

[14] Belletti B, Cerioni R, Iori I. Physical approach for reinforced-concrete (PARC) membrane elements. J Struct Eng 2001;127(12):1412-26.

[15] Walraven J, Belletti B, Esposito R. Shear capacity of normal, lightweight, and high-strength concrete beams according to model code 2010. I: experimental results versus analytical model results. J Struct Eng 2013;139(9):1593-9.

[16] Plos M, Shu J, Zandi K, Lundgren K. A multi-level structural assessment strategy for reinforced concrete bridge deck slabs. Struct Infrastruct Eng 2016:13(2):223-41.

[17] Ozbolt J, Vocke H, Eligehausen R. Three-dimensional numerical analysis of punching failure. Trita-BKN Bull 2000;57:65-74.

[18] Zheng Y, Robinson D, Taylor S, Cleland D. Finite element investigation of the structural behaviour of deck slabs in composite bridges. Eng Struct Aug. 2009;31(8):1762-76.

[19] Amir S. Compressive membrane action in prestressed concrete deck slabs PhD Thesis. Delft: Delft University of Technology; 2014.

[20] Shu J, Fall D, Plos M, Zandi K, Lundgren K. Development of modelling strategies for two-way RC slabs. Eng Struct 2015;101:439-49.

[21] Shu J, Plos M, Johansson M, Zandi K, Nilenius F. Prediction of punching behaviour of RC slabs using continuum non-linear FE analysis. Eng Struct 2016.

[22] Shu J. Structural analysis of existing RC bridge deck slabs. Chalmers University of Technology, Licentiate Thesis, Gothenburg. ISSN 1652-9146; 2015.

[23] Muttoni A. Punching shear strength of reinforced concrete slabs. ACI Struct J 2009;105:440-50.

[24] Einpaul J, Bujnak J, Fernández Ruiz M, Muttoni A. Study on influence of column size and slab slenderness on punching strength. ACI Struct J 2016:113:135-46.

[25] Guandalini S, Burdet OL, Muttoni A. Punching tests of slabs with low reinforcement ratios. ACI Struct J 2009;87-95.

[26] Muttoni A, Ruiz MF. Levels-of-approximation approach in codes of practice. Struct Eng Int 2012;22(2):190-4. 
[27] Muttoni A, Ruiz MF. The levels-of-approximation approach in MC 2010: application to punching shear provisions. Struct Concr 2012;13(1): $32-41$.

[28] Vecchio FJ, Collins MP. Compression response of cracked reinforced concrete. ] Struct 1994;119(12):241-8.

[29] TNO. Diana finite element analysis. User's Manual - Release 9.6. Delft; 2015

[30] Hsieh SS, Ting EC, Chen WF. An elastic-fracture model for concrete. In: Proceedings of the 3rd Engineering Mechanics Division special conference, American Society of Civil Engineers, Austin, Tex.; 1979. p. 437-40.
[31] Fall D, Shu J, Rempling R, Lundgren K, Zandi K. Two-way slabs: experimental investigation of load redistributions in steel fibre reinforced concrete. Eng Struct Dec. 2014;80:61-74.

[32] European Concrete Platform. Eurocode 2 Commentary. Brussels; 2008.

[33] Guandalini S, Muttoni A. Symmetrical punching tests on slabs without transverse reinforcement. Doctoral Thesis, Lausanne, Switland; 2004.

[34] Kinnunen S, Nylander H. Punching of concrete slabs without shear reinforcement. Transactions of the Royal Institute of Technology, No. 158, Stockholm, Sweden; 1960. 